\title{
$\alpha 6^{*}$ Nicotinic Acetylcholine Receptor Expression and Function in a Visual Salience Circuit
}

\author{
Elisha D.W. Mackey, ${ }^{2}$ Staci E. Engle, ${ }^{1}$ Mi Ran Kim, ${ }^{1}$ Heidi C. 0 'Neill, ${ }^{3}$ Charles R. Wageman, ${ }^{3}$ Natalie E. Patzlaff, ${ }^{3}$ \\ Ying Wang, ${ }^{2}$ Sharon R. Grady, ${ }^{3}$ J. Michael McIntosh, ${ }^{4}$ Michael J. Marks, ${ }^{3}$ Henry A. Lester, ${ }^{2}$ and Ryan M. Drenan ${ }^{1}$ \\ ${ }^{1}$ Department of Medicinal Chemistry and Molecular Pharmacology, Purdue University, West Lafayette, Indiana 47907, ${ }^{2}$ Division of Biology, California \\ Institute of Technology, Pasadena, California 91125, ${ }^{3}$ Institute for Behavioral Genetics, University of Colorado Boulder, Boulder, Colorado 80309, and \\ ${ }^{4}$ Departments of Psychiatry and Biology, University of Utah, Salt Lake City, Utah 84112
}

Nicotinic acetylcholine receptors (nAChRs) containing $\alpha 6$ subunits are expressed in only a few brain areas, including midbrain dopamine (DA) neurons, noradrenergic neurons of the locus ceruleus, and retinal ganglion cells. To better understand the regional and subcellular expression pattern of $\alpha 6$-containing nAChRs, we created and studied transgenic mice expressing a variant $\alpha 6$ subunit with green fluorescent protein (GFP) fused in-frame in the M3-M4 intracellular loop. In $\alpha 6$-GFP transgenic mice, $\alpha 6$-dependent synaptosomal DA release and radioligand binding experiments confirmed correct expression and function in vivo. In addition to strong $\alpha 6^{*} \mathrm{nAChR}$ expression in glutamatergic retinal axons, which terminate in superficial superior colliculus (sSC), we also found $\alpha 6$ subunit expression in a subset of GABAergic cell bodies in this brain area. In patch-clamp recordings from sSC neurons in brain slices from mice expressing hypersensitive $\alpha 6^{\star}$ nAChRs, we confirmed functional, postsynaptic $\alpha 6^{\star}$ nAChR expression. Further, sSC GABAergic neurons expressing $\alpha 6^{\star} \mathrm{nAChRs}$ exhibit a tonic conductance mediated by standing activation of hypersensitive $\alpha 6^{*} \mathrm{nAChRs}$ by ACh. $\alpha 6^{*}$ $\mathrm{nAChRs}$ also appear in a subpopulation of SC neurons in output layers. Finally, selective activation of $\alpha 6^{*} \mathrm{nAChRs}$ in vivo induced sSC neuronal activation as measured with c-Fos expression. Together, these results demonstrate that $\alpha 6^{*}$ nAChRs are uniquely situated to mediate cholinergic modulation of glutamate and GABA release in SC. The SC has emerged as a potential key brain area responsible for transmitting short-latency salience signals to thalamus and midbrain DA neurons, and these results suggest that $\alpha 6^{\star} \mathrm{nAChRs}$ may be important for nicotinic cholinergic sensitization of this pathway.

\section{Introduction}

Nicotinic acetylcholine receptors containing $\alpha 6$ subunits $\left(\alpha 6^{*}\right.$ nAChRs) exhibit a unique expression pattern in the mammalian brain. Using radiolabeled $\alpha$-conotoxin-MII, a cone snail toxin selective for $\alpha 3 / \alpha 6 \beta 2^{*} \mathrm{nAChRs,} \alpha 6^{*} \mathrm{nAChRs}$ have been localized chiefly to ventral tegmental area (VTA) and substantial nigra pars compacta (SNc) dopamine (DA) neurons, norepinephrine (NE)producing locus ceruleus (LC) neurons, and optic nerve axons and their terminal areas (Whiteaker et al., 2000b; Champtiaux et al., 2002; Gotti et al., 2005; Cox et al., 2008). Native $\alpha 6^{*}$ nAChRs exhibit a variety of alternative stoichiometries. In DA neurons, $\alpha 6$ subunits require $\beta 2$ subunits (Salminen et al., 2004), but assemble with and without $\alpha 4$ and $\beta 3$ (Salminen et al., 2007; Drenan et al., 2010). LC NE neurons likely produce both $\alpha 6 \beta 4^{*}$ and $\alpha 6 \beta 2^{*}$

Received Jan. 2, 2012; revised April 14, 2012; accepted May 14, 2012.

Author contributions: E.D.W.M., H.C.O., S.R.G., M.J.M., and R.M.D. designed research; E.D.W.M., S.E.E., M.R.K., H.C.O., C.R.W., N.E.P., Y.W., S.R.G., M.J.M., and R.M.D. performed research; Y.W. contributed unpublished reagents/ analytic tools; E.D.W.M., S.E.E., M.R.K., H.C.O., Y.W., S.R.G., M.J.M., H.A.L., and R.M.D. analyzed data; E.D.W.M., S.R.G., J.M.M., M.J.M., H.A.L., and R.M.D. wrote the paper.

This work was supported by NIH Grants DA030396, DA17279, DA12242, DA015663, DA03194, MH53631, and GM48677. Thanks to the Purdue Histology and Phenotyping Laboratory (Purdue University, School of Veterinary Medicine) for technical assistance with histology procedures.

The authors declare no competing financial interests.

Correspondence should be addressed to Ryan M. Drenan, Department of Medicinal Chemistry and Molecular Pharmacology, Purdue University, 575 Stadium Mall Drive, West Lafayette, IN 47907. E-mail: drenan@purdue.edu. DOI:10.1523/JNEUROSCI.0007-12.2012

Copyright $\odot 2012$ the authors $\quad 0270-6474 / 12 / 3210226-12 \$ 15.00 / 0$
nAChRs (Léna et al., 1999; Azam and McIntosh, 2006; Azam et al., 2010). Retinal axons contain a variety of $\alpha 6^{\star} \mathrm{nAChRs,} \mathrm{includ-}$ ing $\alpha 4 \alpha 6 \beta 2 \beta 3^{\star}, \alpha 3 \alpha 4 \alpha 6 \beta 2^{\star}, \alpha 3 \alpha 6 \beta 2$, and $\alpha 6 \beta 2 \beta 3^{\star}$ (Cox et al., 2008).

Studies of $\alpha 6^{*}$ nAChR function in vivo have led to several important findings. $\alpha 6$ knock-out (KO) mice have decreased nicotinestimulated DA release (Champtiaux et al., 2003) and acute intravenous (IV) nicotine self-administration (Pons et al., 2008). IV self-administration is restored by selective re-expression of $\alpha 6$ in VTA (Pons et al., 2008). Chronic intracranial nicotine selfadministration is largely normal in $\alpha 6 \mathrm{KO}$ mice, but activitydependent DA release in striatum is perturbed in these animals (Exley et al., 2011). In rats, VTA $\alpha 6^{*}$ nAChRs mediate the psychomotor stimulant effect of systemic nicotine (Gotti et al., 2010). Mice that express hypersensitive $\alpha 6^{*}$ L9'S nAChRs exhibit spontaneous locomotor hyperactivity and nicotine-stimulated locomotor activation at doses specific for $\alpha 6^{\star} \mathrm{nAChRs}$ (Drenan et al., 2008a). These phenotypes likely arise from enhanced activity of ventral midbrain DA neurons in response to $\alpha 6^{*} \mathrm{nAChR}$ activation (Drenan et al., 2008a), and/or altered activity-dependent DA release in striatum (Drenan et al., 2010).

DA neurons switch among tonic firing $(1-5 \mathrm{~Hz})$, phasic firing $(20-100 \mathrm{~Hz})$, and brief cessation of firing depending on the value of received versus expected outcomes. Recently, it has been appreciated that the superior colliculus (SC) sends excitatory projections to midbrain DA neurons, influencing their firing activity 
and DA release in striatum (Comoli et al., 2003; Dommett et al., 2005; May et al., 2009). $\alpha$ CtxMII-sensitive $\left(\alpha 3^{*}\right.$ or $\left.\alpha 6^{*}\right)$ nAChRs are expressed at extremely high density in superficial layers of SC (Whiteaker et al., 2000b; Champtiaux et al., 2002; Cox et al., 2008). $\alpha$ CtxMII-sensitive nAChRs were also detected postsynaptically in SC (Endo et al., 2005), but the subunit composition of these receptors was not determined. To gain a better understanding of $\alpha 6^{\star} \mathrm{nAChR}$ expression, we generated and studied a bacterial artificial chromosome (BAC) transgenic mouse expressing a variant $\alpha 6$ subunit with enhanced GFP fused in-frame in the M3/M4 intracellular loop. Also, we recorded from SC neurons in mice expressing a hypersensitive variant of the mouse $\alpha 6$ subunit ( $\alpha 6$ L9'S). In these studies, we demonstrate high levels of expression of $\alpha 6^{\star}$ nAChRs in the DA system, and we reveal new details regarding $\alpha 6^{\star} \mathrm{nAChR}$ expression and function in mouse visual system.

\section{Materials and Methods}

Materials. $\left[{ }^{3} \mathrm{H}\right]$-dopamine was obtained from PerkinElmer $\left(7,8-\left[{ }^{3} \mathrm{H}\right]\right.$ at $30-50 \mathrm{Ci} / \mathrm{mmol})$. HEPES, free acid, and sodium salt were products of Amresco. Ultra centrifugation grade sucrose was obtained from Fisher Chemicals. Sigma-Aldrich was the source for the following compounds: $\mathrm{L}(+)$-arabinose, ascorbic acid, atropine sulfate, bovine serum albumin (BSA), (-)-nicotine tartrate, nomifensine, streptomycin, ampicillin, chloramphenicol, kanamycin, tetracycline, and pargyline. Optiphase "SuperMix" scintillation fluid was from PerkinElmer Life Sciences. $\alpha$-Conotoxin MII was synthesized by previously described methods (Azam et al., 2010).

$B A C$ recombineering and transgenesis. $\alpha 6 \mathrm{~L} 9$ 'S mice were described previously (Drenan et al., 2008a), and served as a model for creation of $\alpha 6$-GFP mice. BAC RP24-149I12 containing the mouse $\alpha 6$ nicotinic receptor subunit gene (Chrna6) was obtained from the BACPAC Resource Center at Children's Hospital Oakland Research Institute (Oakland, CA). BAC recombineering was performed using a Counter Selection BAC modification kit (Genebridges). Recombineering in bacteria uses endogenous recombination activity, and allows the insertion of exogenous DNA into the BAC without residual sequences such as selection markers (neo) or loxP sites. $\alpha 6$ wild-type (WT) was mutated to $\alpha 6$-GFP using a two-step selection/counter selection protocol, similar to a previous study (Drenan et al., 2008a). First, a cassette containing a tandem selection (neo)/counter selection (rpsL) marker was introduced after the alanine at position 405, a previously tested insertion site for GFP (Drenan et al., 2008b). The rpsL/neo cassette was amplified by PCR using oligos designed to engineer $\alpha 6$ exon 5 homology arms flanking the sequence through A405 and after A405. The oligo sequences were as follows: forward primer: $5^{\prime}-\mathrm{cc}$ aaa ctt cta aag gaa tgc cac cac tgc caa aaa tca agt gac ata gca gtcgac GGC CTG GTG ATG ATG GCG GGA TCG-3' and reverse primer: $5^{\prime}-\mathrm{tt}$ ctc tgc cac cca ccg tgc agg ctg ctg gct tga tct tct ctt tcc agg gtcgac TCA GAA GAA CTC GTC AAG AAG GCG-3' (homology arms: lower case; SalI restriction site: underlined, lower case; rpsL/neo cassette priming sequence: upper case).

Neo was used to select positive recombinants, and an engineered SalI restriction site pair flanking the selection cassette was used to confirm the location of the exogenously inserted DNA within the BAC. In the second step, GFP was inserted and screened using counter selection. Bacterial cells were placed under selective pressure (via streptomycin sensitivity gained by insertion of the rpsL marker) to lose the neo-rpsL cassette and replace it with a nonselectable GFP cassette. The GFP cassette was amplified by PCR using oligos containing the same $\alpha 6$ exon 5 homology arms as the rpsL/neo cassette. Instead of a Sall restriction site, the GFP was flanked with a small, three amino acid linker, A-G-A, that also contains a KasI restriction site. The GFP cassette was amplified using the oligo sequences: $5^{\prime}$-cc aaa ctt cta aag gaa tgc cac cac tgc caa aaa tca agt gac ata gca gct ggc gec ATG GTG AGC AAG GGC GAG GAG-3' and 5' - tt ctc tgc cac cca ccg tgc agg ctg ctg get tga tct tct ctt tcc agg ggc gcc tgc CTT GTA CAG CTC GTC CAT (homology arms: lower case; A-G-A linker: underlined, lower case; GFP cassette priming sequence: upper case). The resul- tant strain harbored a BAC with no ectopic DNA in or around the $\alpha 6$ gene. $\alpha 6$-GFP BAC DNA was confirmed to have the desired mutation by DNA sequencing, restriction mapping, and diagnostic PCR. The $\alpha 6$ nicotinic receptor gene is directly adjacent to the $\beta 3$ nicotinic receptor gene (Chrnb3). To eliminate the possibility that any physiological or behavioral phenotypes of our transgenic mice could be attributed to the presence of extra copies of $\beta 3$, but to retain the $\beta 3$ locus, we silenced the $\beta 3$ gene using homologous recombination. $\beta 3$ was silenced by replacing exon 1 (containing the methionine initiation codon) with an ampicillin selection cassette. An ampicillin marker derived from pCDNA3.1zeo was amplified by PCR using oligos designed to engineer $\beta 3$ homology arms and diagnostic $S b f 1$ restriction sites flanking the ampicillin marker. The oligo sequences were as follows: forward primer: $5^{\prime}$-agc ctc aca aga cct gac agc tca ctg ggc atc agt gaa gtg cac cctgcagg GAC GTC AGG TGG CAC-3' and reverse primer: $5^{\prime}$-tga gag agt ggc act gag agc caa gaa gac ccg tag gaa gcc tgt cctgcagg GTC TGA CGC TCA GTG-3' (homology arms: lower case; $S b f$ l restriction site: underlined, lower case; ampicillin marker priming sequence: upper case). Two additional genes (4921537P18Rik and Tex24), which are not expressed in brain, are also contained on the final BAC construct.

Injection-grade $\alpha 6$-GFP BAC DNA was prepared via double $\mathrm{CsCl}$ banding (Lofstrand Labs). To produce transgenic animals, BAC DNA was injected into the pronucleus of fertilized B6D2F1 ova and implanted into pseudopregnant Swiss-Webster surrogates. Several transgenic founders were identified using tail biopsy DNA and PCR primers designed to detect both the GFP mutation (forward: $5^{\prime}$-ctc cgt tct gtc aag ctt g- $3^{\prime}$, reverse: $5^{\prime}$-acg agt gct ctg aat tct ctg- $\left.3^{\prime}\right)$, and the inserted ampicillin cassette within the $\beta 3$ gene (forward: $5^{\prime}$-gct cat gag aca ata acc ctg- $3^{\prime}$, reverse: $5^{\prime}$-cag tct tgg aag caa cat cca gc- $3^{\prime}$ ). One transgenic line, "line 4 ," is reported in detail in this study. Founders were crossed to C57BL/6J (The Jackson Laboratory) to obtain germline transmission and to establish a colony, and transgenic mice were continually backcrossed to C57BL/6J. Routine genotyping was done by multiplex PCR (forward primer \#1: $5^{\prime}$-tga tga tga gga aac ctc tgg- $3^{\prime}$; forward primer \#2: $5^{\prime}$-ctg ctg ctc atc acc gag atc- $3^{\prime}$; reverse primer $\# 1$ : $5^{\prime}$-gtc gtg ctg ctt cat gtg gtc g- $3^{\prime}$; and reverse primer $\# 2: 5^{\prime}$-cag atg tca ccc aag atg ccg- $3^{\prime}$ ) analysis of tail DNA from newly weaned mice. $\alpha 6$-GFP BAC copy number was calculated using the comparative $C_{T}$ method following real-time PCR (Livak and Schmittgen, 2001; Ballester et al., 2004; Lee et al., 2006; Schmittgen and Livak, 2008), as previously described (Cohen et al., 2012). $\alpha 6$-GFP transgenic mice contained six copies of the $\alpha 6$-GFP BAC.

Mice. All experiments were conducted in accordance with the guidelines for care and use of animals provided by the National Institutes of Health (NIH), and protocols were approved by the Institutional Animal Care and Use Committee at Purdue University, the California Institute of Technology, or the University of Colorado. Mice were kept on a standard $12 \mathrm{~h} \mathrm{light/dark} \mathrm{cycle} \mathrm{at} 22^{\circ} \mathrm{C}$ and given food and water ad libitum. On P21, mice were weaned and housed with same-sex littermates. At 21 to $28 \mathrm{~d}$, tail biopsies were taken for genotype analysis by PCR. Tails were digested in $50 \mathrm{~mm} \mathrm{NaOH}$ at $95^{\circ} \mathrm{C}$ for $45 \mathrm{~min}$ followed by neutralization with $0.5 \mathrm{M}$ Tris-Cl, pH 5.5, and subsequent direct analysis by multiplex PCR.

Neurotransmitter release from synaptosomes. Previously described methods were followed for measuring DA release (Salminen et al., 2007). Briefly, appropriate brain regions were homogenized in $0.5 \mathrm{ml}$ of ice-cold $0.32 \mathrm{M}$ sucrose buffered with $5 \mathrm{~mm}$ HEPES, $\mathrm{pH}$ 7.5. A crude synaptosomal pellet was prepared by centrifugation at $12,000 \times g$ for $20 \mathrm{~min}$. The pellets were resuspended in "uptake buffer" containing the following (in mM): $128 \mathrm{NaCl}, 2.4 \mathrm{KCl}, 3.2 \mathrm{CaCl}_{2}, 1.2 \mathrm{KH}_{2} \mathrm{PO}_{4}, 1.2 \mathrm{MgSO}_{4}, 25 \mathrm{HEPES}$, $\mathrm{pH} 7.5$, and 10 glucose, supplemented with 1 ascorbic acid and 0.01 pargyline. After incubation at $37^{\circ} \mathrm{C}$ for $10 \mathrm{~min},\left[{ }^{3} \mathrm{H}\right]-\mathrm{DA}(0.1 \mu \mathrm{M})$ was added and incubation continued for $5 \mathrm{~min}$.

All superfusion experiments were conducted at room temperature (RT) using methods described previously (Salminen et al., 2007; McClure-Begley et al., 2009). In brief, aliquots of synaptosomes were distributed onto filters and superfused with buffer (uptake buffer containing $0.1 \% \mathrm{BSA}$ and $1 \mu \mathrm{M}$ atropine with $1 \mu \mathrm{M}$ nomifensine) at 0.7 $\mathrm{ml} / \mathrm{min}$ for $10 \mathrm{~min}$, or buffer for $5 \mathrm{~min}$ followed by buffer with $50 \mathrm{nM}$ $\alpha$ CtxMII. Aliquots of synaptosomes were then exposed to nicotine or high potassium $(20 \mathrm{~mm})$ in buffer for $20 \mathrm{~s}$ to stimulate release of $\left[{ }^{3} \mathrm{H}\right]-$ 
DA, followed by buffer. Fractions $(\sim 0.1 \mathrm{ml})$ were collected for $4 \mathrm{~min}$ into 96 -well plates at $10 \mathrm{~s}$ intervals, starting from $1 \mathrm{~min}$ before stimulation, using a Gilson FC204 fraction collector with a multicolumn adapter. Radioactivity was determined by scintillation counting using a 1450 MicroBeta Trilux scintillation counter (PerkinElmer Life Sciences) after addition of $0.15 \mathrm{ml}$ Optiphase "SuperMix" scintillation mixture. Instrument efficiency was $40 \%$.

Perfusion data were plotted as counts per minute versus fraction number. Fractions collected before and after the peak were used to calculate baseline as a single exponential decay. The calculated baseline was subtracted from the experimental data. Fractions that exceeded baseline by $10 \%$ or more were summed to give total released counts per minute (cpm) and then normalized to baseline to give units of release [(cpm-baseline)/ baseline] (Drenan et al., 2008a, 2010). Agonist dose-response data were fit to the Hill equation.

Patch-clamp electrophysiology. For slice electrophysiology, transgenic and nontransgenic mice were identified by genotyping new litters at 14-18 d after birth. P17-P25 mice were anesthetized with sodium pentobarbital (100 $\mathrm{mg} / \mathrm{kg}$; i.p.) followed by cardiac perfusion with oxygenated $\left(95 \% \quad \mathrm{O}_{2} / 5 \% \quad \mathrm{CO}_{2}\right) \quad$ ice-cold glycerol-based artificial CSF (gACSF) containing the following in (mM): 252 glycerol, 1.6 $\mathrm{KCl}, 1.2 \mathrm{NaH}_{2} \mathrm{PO}_{4}, 1.2 \mathrm{MgCl}_{2}, 2.4 \mathrm{CaCl}_{2}, 18$ $\mathrm{NaHCO}_{3}$, and 11 glucose. Following perfusion, brains were removed and retained in gACSF $\left(0-4^{\circ} \mathrm{C}\right)$. Coronal slices $(250 \mu \mathrm{m})$ were cut with a microslicer (DTK-Zero 1 ; Ted Pella) at a frequency setting of 9 and a speed setting of 3.25. Brain slices were allowed to recover for at least $1 \mathrm{~h}$ at $32^{\circ} \mathrm{C}$ in regular, oxygenated ACSF containing the following (in $\mathrm{mM}$ ): $126 \mathrm{NaCl}$, $1.6 \mathrm{KCl}, 1.2 \mathrm{NaH}_{2} \mathrm{PO}_{4}, 1.2 \mathrm{MgCl}_{2}, 2.4 \mathrm{CaCl}_{2}$, $18 \mathrm{NaHCO}_{3}$, and 11 glucose.

For recordings, a single slice was transferred to a $0.8 \mathrm{ml}$ recording chamber $(\mathrm{RC}-27 \mathrm{~L}$ bath with $\mathrm{PH}-6 \mathrm{D}$ heated platform; Warner Instruments). Slices were continually superfused with ACSF (1.5-2.0 $\mathrm{ml} / \mathrm{min})$ throughout the experiment. Cells were visualized with an upright microscope (FN-1; Nikon) using infrared or visible differential interference contrast optics. Patch electrodes were constructed from Kwik-Fil borosilicate glass capillary tubes (1B150F-4; World Precision Instruments) using a programmable microelectrode puller $(\mathrm{P}-$ 97; Sutter Instrument). The electrodes had tip resistances of 4.5-8.0 M $\Omega$ when filled with internal pipette solution $(\mathrm{pH}$ adjusted to 7.25 with Tris base, osmolarity adjusted to 290 mOsm with sucrose) containing the following (in $\mathrm{mm}$ ): $135 \mathrm{~K}^{+}$gluconate, 5 EGTA, $0.5 \mathrm{CaCl}_{2}, 2 \mathrm{MgCl}_{2}, 10 \mathrm{HEPES}, 2 \mathrm{Mg}$-ATP, and $0.1 \mathrm{GTP}$. Whole-cell recordings were taken at $32^{\circ} \mathrm{C}$ with an Axopatch $200 \mathrm{~B}$ amplifier, a 16-bit Digidata 1440A A/D converter, and pCLAMP 10 software (all Molecular Devices Axon). Data were sampled at $5 \mathrm{kHz}$ and lowpass filtered at $1 \mathrm{kHz}$. The junction potential between the patch pipette and the bath solution was nulled immediately before gigaseal formation. Series resistance was uncompensated.

To examine the function of somatic nAChRs, nicotine was locally applied using a Picospritzer III (General Valve). Using a high-resolution plexiform layer.
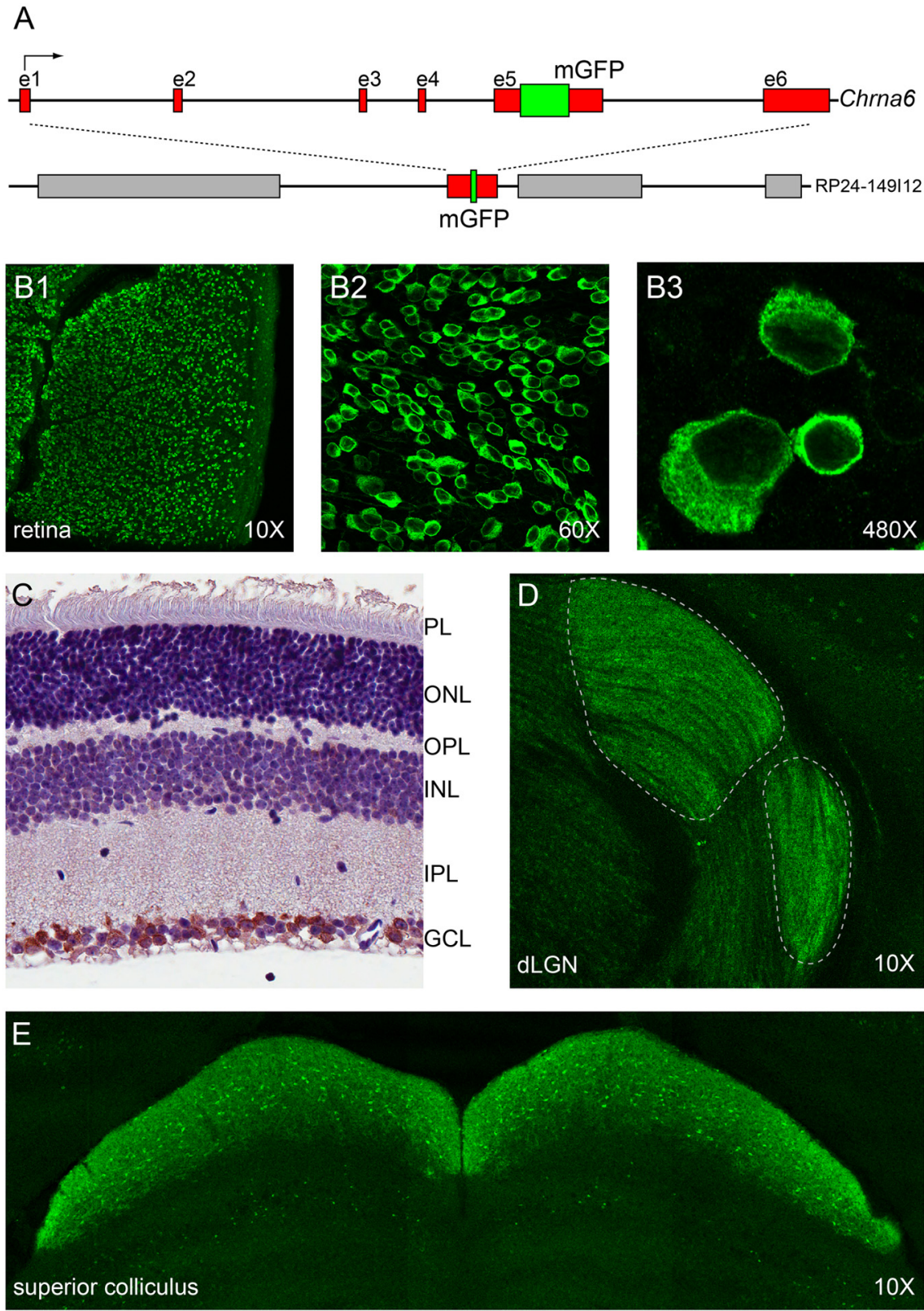

Figure 1. Production of $\alpha 6$-GFP BAC transgenic mice and $\alpha 6^{*} \mathrm{nAChR}$ expression in visual system. $\mathrm{A}$, Construction of $\alpha 6$-GFP $\mathrm{BAC}$ transgene. A BAC containing the full Chrna6 gene was modified by recombineering to allow expression of a variant $\alpha 6 \mathrm{nAChR}$ subunit with GFP fused in-frame within the M3-M4 intracellular loop. B, C, $\alpha 6^{*}$ nAChR expression in retina. Whole-mount retinal sections were prepared from $\alpha 6$-GFP transgenic mice and stained with anti-GFP antibodies. GFP $(+)$ cells in the GCL were imaged with confocal microscopy at $10 \times(B 1), 60 \times(B 2)$, and $480 \times(B 3)$. Retinal cross sections were prepared from $\alpha 6$-GFP transgenic mice ( $($ ), followed by anti-GFP staining (brown color) and hematoxylin counterstaining to label nuclei. $\alpha 6$ immunoreactivity was confined to the GCL. D, $\boldsymbol{E}, \alpha 6^{*}$ nAChR expression in visual thalamus and SC. Brains from $\alpha 6$-GFP transgenic mice were fixed, sectioned at $50 \mu \mathrm{m}$ (coronal), and stained with anti-GFP antibodies. dLGN (D) and SC (E) stained positive for $\alpha 6^{*} \mathrm{nAChR}$ expression. PL, photoreceptor layer; $\mathrm{ONL}$, outer nuclear layer; $\mathrm{OPL}$, outer plexiform layer; INL, inner nuclear layer; IPL, inner

micromanipulator (Sutter Instruments), the pipette tip was moved within $20-40 \mu \mathrm{m}$ of the recorded cell $1-2 \mathrm{~s}$ before drug application. Nicotine-containing recording solution was then puffed at $10-20$ psi for $250 \mathrm{~ms}$. Immediately after the application, the glass pipette was retracted.

$\mathrm{Rb}^{+}$efflux from SC synaptosomes. Nicotine-stimulated $\mathrm{Rb}^{+}$efflux from SC was measured as described previously (Nashmi et al., 2007). Briefly, SC was dissected from adult mice and crude synaptosomes prepared as described above for neurotransmitter release. Each pellet was resuspended in load buffer $(140 \mathrm{~mm} \mathrm{NaCl}, 1.5 \mathrm{~mm} \mathrm{KCl}, 2 \mathrm{~mm} \mathrm{CaCl}, 1$ $\mathrm{mm} \mathrm{MgSO}_{4}, 25 \mathrm{~mm}$ HEPES, and $22 \mathrm{~mm}$ glucose) and aliquots incubated 

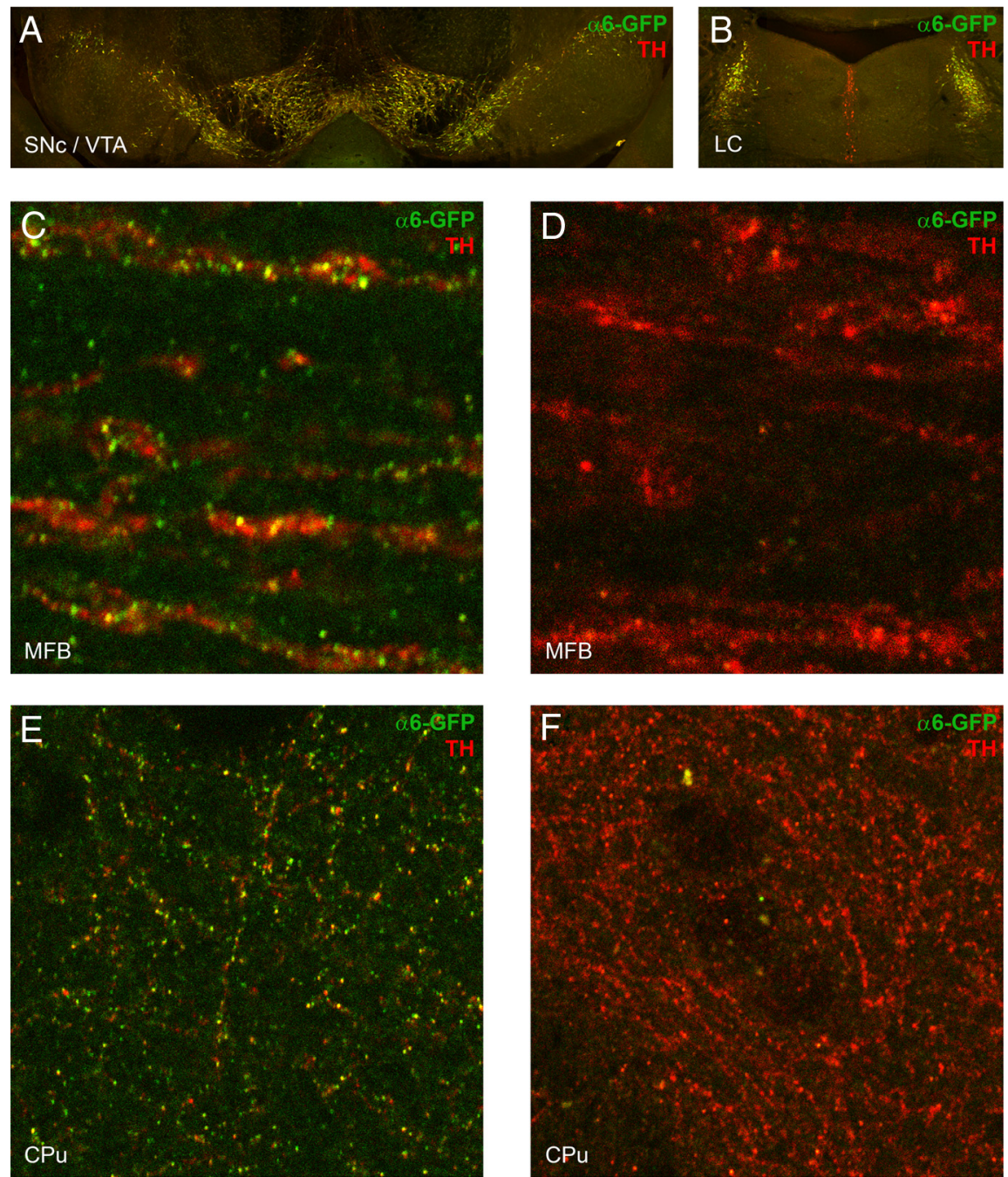

Figure 2. $\alpha 6^{*} \mathrm{nAChR}$ expression in catecholamine-producing neurons. $\boldsymbol{A}, \alpha 6^{*} \mathrm{nAChR}$ expression in ventral midbrain DA neurons. Coronal sections (bregma $-3.5 \mathrm{~mm}$ ) were prepared from $\alpha 6$-GFP transgenic mice, followed by dual staining with anti-GFP and anti- TH antibodies to label DA neurons. Sections were imaged with laser-scanning confocal microscopy, and fluorescence from both channels (green, anti-GFP; red, anti-TH) were merged to indicate coexpression of $\alpha 6^{*} \mathrm{nAChRs}$ within $\mathrm{TH}(+)$ neurons. $\boldsymbol{B}, \alpha 6^{*}$ nAChR expression in LC NE neurons. Coronal sections (bregma $-5.52 \mathrm{~mm}$ ) from $\alpha 6$-GFP transgenic mice containing $\mathrm{LC}$ were prepared and double stained as described in $\boldsymbol{A}$. C, $\boldsymbol{D}, \alpha 6^{*} \mathrm{nAChR}$ expression in DA axons. Sagittal sections (lateral $0.96 \mathrm{~mm}$ ) containing medial forebrain bundle (MFB) DA axons were prepared from $\alpha 6$-GFP transgenic mice $(C)$ and nontransgenic control mice (D). Sections were stained for GFP and TH as in $\boldsymbol{A}$ and $\boldsymbol{B}$. GFP and TH channels were merged, and yellow indicates $\alpha 6$-GFP staining within TH(+) DA axons. $\boldsymbol{E}, \boldsymbol{F}, \alpha 6^{*} \mathrm{nAChR}$ expression in DA terminals in striatum. Coronal sections (bregma $+0.14 \mathrm{~mm}$ ) from $\alpha 6$-GFP transgenic mice $(\boldsymbol{E})$ and nontransgenic control mice $(\boldsymbol{F})$ containing dorsal striatum were prepared, stained for GFP and TH, and imaged as above. Yellow indicates $\alpha 6$-GFP staining within $\mathrm{TH}(+)$ DA terminals. $\mathrm{CPu}$, caudate putamen.

with $4 \mu \mathrm{Ci}$ of ${ }^{86} \mathrm{Rb}^{+}$for $30 \mathrm{~min}$ in a final volume of $35 \mu \mathrm{l}$ of load buffer. Filters containing the synaptosomes loaded with ${ }^{86} \mathrm{Rb}^{+}$were superfused for $5 \mathrm{~min}$ with buffer $(135 \mathrm{~mm} \mathrm{NaCl}, 1.5 \mathrm{~mm} \mathrm{KCl}, 5 \mathrm{~mm} \mathrm{CsCl}, 2 \mathrm{~mm}$ $\mathrm{CaCl}_{2}, 1 \mathrm{~mm} \mathrm{MgSO}$, 25 mm HEPES, $22 \mathrm{~mm}$ glucose, 50 nм tetrodotoxin (TTX), and $0.1 \%$ BSA) and the effluent was pumped through a $200 \mu \mathrm{l}$ Cherenkov cell and into a $\beta$-Ram detector (IN/US Systems). Radioactivity was measured for $3 \mathrm{~min}$ with a $3 \mathrm{~s}$ detection window providing 60 data points for each superfusion. Each aliquot was stimulated by one of four different nicotine concentrations, with a $5 \mathrm{~s}$ exposure for each concentration.

Epibatidine binding to membranes. Membranes were prepared by previously described procedures (Whiteaker et al., 2000a) from SC, thalamus, striatum (caudate putamen and dorsal nucleus accumbens), olfactory tubercle (OT), cortex, and ventral midbrain, by homogenization in ice-cold hypotonic buffer $(14 \mathrm{~mm} \mathrm{NaCl}, 0.2 \mathrm{~mm} \mathrm{KCl}, 0.2 \mathrm{~mm}$ $\mathrm{CaCl}_{2}, 0.1 \mathrm{~mm} \mathrm{MgSO}_{4}$, and 2 mM HEPES, pH 7.5) using a glass-Teflon tissue grinder. Particulate fractions were obtained by centrifugation at 20,000 $\mathrm{g}$ (15 min, $4^{\circ} \mathrm{C}$ ) and washed by resuspension and centrifugation three times, then stored (in pellet form under homogenization buffer) at $-70^{\circ} \mathrm{C}$ until use. Protein was quantified with a Lowry assay using BSA as the standard.

Binding of $\left[{ }^{125} \mathrm{I}\right]$-epibatidine was quantified using methods previously described (Whiteaker et al., 2000a). Incubations were performed in 96well polystyrene plates, in $30 \mu$ l of binding buffer $(144 \mathrm{~mm} \mathrm{NaCl}, 1.5 \mathrm{~mm} \mathrm{KCl}, 2 \mathrm{~mm} \mathrm{CaCl}, 1 \mathrm{~mm}$ $\mathrm{MgSO}_{4}$ and $20 \mathrm{~mm} \mathrm{HEPES}, \mathrm{pH} 7.5$ ) with $200 \mathrm{pm}$ $\left[{ }^{125} \mathrm{I}\right]$-epibatidine. Binding reactions were terminated by filtration of samples onto a single thickness of polyethyleneimine-soaked $(0.5 \% \mathrm{w} / \mathrm{v}$ in binding buffer) GFA/E glass fiber filters (Gelman Sciences) using an Inotech Cell Harvester. Samples were subsequently washed six times with icecold binding buffer. Bound ligand was quantified by gamma counting at $83-85 \%$ efficiency, using a Packard Cobra counter. In experiments with competitive unlabeled $\alpha \mathrm{CtxMII}$ (50 nM), the medium was supplemented with BSA $(0.1 \% \mathrm{w} / \mathrm{v})$ as a carrier protein. For cytisine inhibition, concentrations of 0,50 , or $150 \mathrm{~nm}$ were added to separate wells and cytisine-sensitive and -resistant binding of $\left[{ }^{125} \mathrm{I}\right]$-epibatidine calculated using the equation $B=\left[B_{H} /\left(1+\left([\mathrm{cyt}] / \mathrm{IC}_{50 \mathrm{H}}\right)\right]+\left[B_{L} /\right.\right.$ $\left(1+\left([\mathrm{cyt}] / \mathrm{IC}_{50 \mathrm{~L}}\right)\right]$ where $B=$ measured binding, $B_{H}$ is binding with high affinity for cytisine, and $B_{L}$ is binding with low affinity for cytisine with respective $\mathrm{IC}_{50}$ values for inhibition of $200 \mathrm{pM}$ epibatidine experimentally determined $\left(\mathrm{IC}_{50 \mathrm{H}}=\right.$ $3.5 \mathrm{~nm} ; \mathrm{IC}_{50 \mathrm{~L}}=290 \mathrm{~nm}$ ). For all experiments, nonspecific binding was determined in the presence of $1 \mathrm{~mm}(-)$-nicotine tartrate.

Immunohistochemistry, c-Fos induction, and confocal imaging. Methods for immunohistochemistry and confocal microscopy are similar to previous studies (Drenan et al., 2008a). For c-Fos experiments, mice were habituated to injections with saline injections for 3-4 $\mathrm{d}$ before the experimental injection. On the experimental day, mice were injected with nicotine $(0.15$ $\mathrm{mg} / \mathrm{kg}$; i.p.), and were perfused for immunohistochemistry $90 \mathrm{~min}$ later, as described below.

Mice were deeply anesthetized with sodium pentobarbital $(100 \mathrm{mg} / \mathrm{kg}$; i.p.) and perfused transcardially with $15 \mathrm{ml}$ of ice-cold PBS followed by $25 \mathrm{ml}$ of ice-cold $4 \%$ paraformaldehyde (PFA) in PBS. Brains were removed and postfixed for $2 \mathrm{~h}$ at $4^{\circ} \mathrm{C}$ with the same fixative and cryoprotected in PBS containing 30\% sucrose until the brain sank. Coronal or sagittal sections $(50 \mu \mathrm{m})$ were cut on a microslicer and collected into a 12-well tissue culture plate containing PBS. Following extraction from eye cups, several relief cuts were made on retinal tissue sheets used for whole-mount analysis, and flattened retinal sections were treated similarly to brain sections, as follows. Sections were permeabilized (20 mм HEPES, pH 7.4, 0.5\% Triton X-100, $50 \mathrm{~mm} \mathrm{NaCl,} 3 \mathrm{~mm}$ $\mathrm{MgCl}_{2}, 300 \mathrm{~mm}$ sucrose) for $1 \mathrm{~h}$ at $4^{\circ} \mathrm{C}$ followed by blocking $(0.1 \%$ Triton $\mathrm{X}-100,5 \%$ donkey serum in TBS) for $1 \mathrm{~h}$ at RT. Slices were incubated overnight at $4^{\circ} \mathrm{C}$ in solutions containing primary antibodies (diluted in $0.1 \%$ Triton X-100, 5\% donkey serum in TBS). Primary antibodies and final dilutions were as follows: 1:500 rabbit anti-GFP (A11122; Invitrogen), 1:500 sheep anti-tyrosine hydroxylase (TH; AB1542, Millipore), 1:500 mouse anti-GAD67 (MAB5406; Millipore), 1:500 mouse antiNeuN (clone A60, MAB377; Millipore), 1:500 guinea pig anti-VGLUT1 
(AB5905; Millipore), and 1:400 rabbit anti-c-Fos (sc-52; Santa Cruz Biotechnology). Sections were washed three times for 10 min each in TBST $(0.1 \%$ Triton X-100 in TBS) and incubated for $1 \mathrm{~h}$ at RT with secondary antibodies (diluted in $0.1 \%$ Triton X-100, 5\% donkey serum in TBS). Secondary antibodies and final dilutions were as follows: 1:1000 goat anti-rabbit Alexa 488 (A11008; Invitrogen), 1:1000 donkey anti-sheep Alexa 555 (A21436; Invitrogen), 1:1000 donkey anti-mouse Alexa 555 (A31570; Invitrogen), and 1:1000 goat anti-guinea pig Alexa 555 (A21435; Invitrogen). Sections were then washed four times in TBST for 10 min each. Sections that were costained with the nuclear dye, Qnuclear, were incubated after the third TBST wash in 1:1000 Qnuclear Deep Red Stain (Q10363; Invitrogen) in PBS for $20 \mathrm{~min}$ at RT followed by three 5 min washes in PBS. All sections were mounted on slides and coverslipped with Vectashield (Vector Laboratories), then imaged with a Nikon (Nikon Instruments) C1 or A1 laser-scanning confocal microscope system equipped with spectral imaging capabilities and a Prior (Rockland) remote-focus device. A Nikon Plan Apo $10 \times$ or $60 \times$ oil objective was used, and pinhole diameter was $30 \mu \mathrm{m}$. Sections were imaged at 12-bit intensity resolution over $512 \times 512$ pixels at a pixel dwell time of 2-4 $\mu$ s. Alexa 488 was excited with an argon laser at 488 $\mathrm{nm}$, and Alexa 555 was excited with a yellow solid-state laser at 561 $\mathrm{nm}$. Qnuclear was excited with a diode laser at $636 \mathrm{~nm}$. Imaging was performed using the Nikon DEES grating and spectral detector with 32 parallel photomultiplier tubes. Signal from dyes was unmixed from background autofluorescence similar to our previous studies (Briggs et al., 2006; Drenan et al., 2008a,b).

Immunohistochemistry on retinal cross sections was performed as follows. Eyes were removed and fixed in 4\% PFA in PBS, followed by paraffin embedding and sectioning at $7 \mu \mathrm{m}$ with a microtome. Epitopes were retrieved with $1 \mathrm{mM} \mathrm{Na}^{+}$citrate buffer ( $\mathrm{pH}$ 6.0), followed by $\mathrm{H}_{2} \mathrm{O}_{2}$ treatment. Sections were blocked, incubated with anti-GFP antibodies (1:200 dilution) for $60 \mathrm{~min}$ at RT, washed, and incubated with anti-rabbit horseradish peroxidase secondary antibodies (K4003, EnVision+ System; Dako) for $45 \mathrm{~min}$ at RT. Sections were reacted with diaminobenzidine reagent for $5 \mathrm{~min}$ at RT, rinsed, stained with hematoxylin for $3 \mathrm{~min}$, rinsed, dehydrated with a graded alcohol series, cleared with xylene, and coverslipped.

Statistics and data analysis. Physiology, neurochemistry, and real-time PCR data are reported as mean \pm SEM. Statistical significance $(p<0.05)$ was determined with a Student's $t$ test for continuous data meeting parametric assumptions for normality and equal variance. Neurochemistry data were analyzed for significance by one-way ANOVA with Tukey's post hoc analysis.

\section{Results \\ Production and characterization of BAC $\alpha 6-$ GFP transgenic mice}

To faithfully express GFP-labeled $\alpha 6^{*} \mathrm{nAChRs}$, we selected a BAC clone (RP24-149I12) containing the Chrna6 ( $\alpha 6$ nAChR) locus. This BAC was used previously to successfully express hypersensitive $\alpha 6$ L9'S nAChRs in their native brain regions. Using a two-step selection/counter selection recombineering protocol, a coding sequence for GFP was inserted in exon 5 of the Chrna6 gene within the coding sequence for the M3-M4 intracellular loop following Ala 405 (Fig. 1A). $\alpha 6$-GFP receptors with this mutation assemble appropriately with $\alpha 4, \beta 2$, and $\beta 3 \mathrm{nAChR}$ subunits, are trafficked to the cell periphery, and their function in electrophysiological assays is comparable to $\alpha 4 \beta 2 \mathrm{nAChRs} \mathrm{(Dre-}$ nan et al., 2008b; Xiao et al., 2011).

Using anti-GFP immunostaining, we characterized $\alpha 6$-GFP expression in the CNS of $\alpha 6$-GFP BAC transgenic mice. Using $\left[{ }^{125} \mathrm{I}\right]-\alpha \mathrm{CtxMII}$, which does not distinguish between $\alpha 3^{\star}$ versus $\alpha 6^{\star}$ nAChRs, investigators have concluded that $\alpha 3^{*}$ and/or $\alpha 6^{*}$ $n A C h R s$ are expressed strongly in visual pathways such as retina, optic nerve, visual thalamus (dorsal lateral geniculate nucleus, dLGN), and SC. We noted strong expression of $\alpha 6$-GFP nAChRs in retinal tissue using whole-mount preparations (Fig. 1B1).
Table 1. Expression levels of $\alpha 6^{*}$ nAChRs in $\alpha 6$-GFP mice determined by radioligand binding assays

\begin{tabular}{lcr}
\hline [225I]-Epibatidine binding & \multicolumn{1}{c}{ Control } & \multicolumn{1}{c}{$\alpha 6$-GFP } \\
\hline CX MII-res & $63.3 \pm 8.2$ & $55.0 \pm 9.5$ \\
CX MII-sens & $2.0 \pm 2.2$ & $0.2 \pm 0.9$ \\
TH MII-res & $101.4 \pm 15.6$ & $99.9 \pm 4.1$ \\
TH MII-sens & $5.3 \pm 2.7$ & $9.8 \pm 1.1$ \\
ST MII-res & $45.6 \pm 4.9$ & $42.5 \pm 2.4$ \\
ST MII-sens & $7.1 \pm 0.9$ & $10.5 \pm 0.8$ \\
OT MII-res & $30.3 \pm 1.9$ & $28.6 \pm 2.3$ \\
OT MII-sens & $7.1 \pm 1.1$ & $6.5 \pm 0.7$ \\
SC MII-res & $73.2 \pm 13.0$ & $81.7 \pm 6.1$ \\
SC MII-sens & $15.1 \pm 1.8$ & $12.7 \pm 7.3$ \\
vMB MII-res & $81.7 \pm 6.8$ & $87.1 \pm 7.6$ \\
VMB MII-sens & $6.0 \pm 1.7$ & $5.8 \pm 2.1$ \\
CX cyt-res & $-0.6 \pm 0.7$ & $-0.2 \pm 0.5$ \\
CX cyt-sens & $65.9 \pm 1.0$ & $55.4 \pm 0.8$ \\
TH cyt-res & $4.3 \pm 1.8$ & $5.0 \pm 1.4$ \\
TH cyt-sens & $102.4 \pm 2.6$ & $104.6 \pm 2.1$ \\
ST cyt-res & $2.1 \pm 0.0$ & $2.1 \pm 0.2$ \\
ST cyt-sens & $47.5 \pm 0.3$ & $52.3 \pm 0.0$ \\
OT cyt-res & $3.8 \pm 0.6$ & $4.3 \pm 0.5$ \\
OT cyt-sens & $34.4 \pm 0.9$ & $29.6 \pm 0.7$ \\
SC cyt-res & $4.9 \pm 1.2$ & $4.8 \pm 0.2$ \\
SC cyt-sens & $79.0 \pm 2.0$ & $86.9 \pm 0.8$ \\
VMB cyt-res & $3.9 \pm 0.8$ & $89.9 \pm 0.8$ \\
vMB cyt-sens & $84.0 \pm 2.0$ & \\
\hline
\end{tabular}

Each indicated brain region was dissected and the tissue was prepared for binding experiments as described in Materials and Methods. Samples were labeled with [ $\left.{ }^{125} 1\right]$-epibatidine with or without competition with excess, unlabeled $\alpha$ CtxMIII or cytisine. $\alpha$ CtxMII and cytisine-sensitive and -resistant components are shown. For all experiments, data from groups of $\alpha 6$-GFP and control (nontransgenic) littermate mice were compared. CX, cortex; 0T, olfactory tubercle; SC, superior colliculus; $\mathrm{ST}$, dorsal striatum; $\mathrm{TH}$, thalamus; vMB, ventral midbrain. Data (in fmol/mg protein) are mean \pm SEM ( $n=5$ mice)

Strong expression was noted in the retinal ganglion cell (RGC) layer in this preparation (Fig. 1B2). In presumptive RGCs, $\alpha 6$ GFP nAChRs were expressed throughout the cell periphery, and were not concentrated on the cell surface (Fig. 1 B3). To confirm that $\alpha 6^{*} \mathrm{nAChRs}$ are expressed in RGCs, we prepared retinal cross sections and stained the tissue with anti-GFP antibodies. $\alpha 6$-GFP nAChRs were localized exclusively in the ganglion cell layer (GCL) in these sections (Fig. $1 C$ ), where we noted $\alpha 6$-GFP expression in $52 \pm 2 \%$ of cells in this layer (data not shown). Additionally, $\alpha 6$-GFP nAChRs were strongly expressed in dLGN in thalamus (Fig. 1D) and in SC (Fig. 1E). $\alpha 6$-GFP nAChRs were also localized to optic tract axons, and to the medial terminal nucleus of the accessory optic tract (data not shown). These results are consistent with previous reports using $\left[{ }^{125} \mathrm{I}\right]-\alpha \mathrm{CtxMII}$ autoradiography, and with studies in $\alpha 6 \mathrm{KO}$ mice (Whiteaker et al., 2000b; Champtiaux et al., 2002).

Others have previously demonstrated robust expression of $\alpha 6$ nAChR mRNA in DA neurons in SNc and VTA, and in NE neurons in LC (Le Novère et al., 1996; Léna et al., 1999; Azam et al., 2002). At the protein level in $\alpha 6$-GFP mice, we found robust expression of $\alpha 6$-GFP nAChRs in these areas. Using dual antiGFP and anti-TH immunostaining, we show that $\alpha 6^{*}$ nAChRs are specifically expressed in TH-expressing DA (Fig. $2 A$ ) or NE (Fig. $2 B$ ) neurons in these brain regions. In VTA, $\alpha 6$ subunits were expressed in $88 \pm 2 \%$ of $\mathrm{TH}(+)$ neurons, and in SNc, $\alpha 6$ subunits were expressed in $98 \pm 1 \%$ of $\mathrm{TH}(+)$ neurons $(n=2$ mice; data not shown). These results are highly consistent with previous similar studies using $\alpha 6$ mRNA in situ hybridization (Azam et al., 2002). We did not find expression of $\alpha 6^{\star}$ nAChRs in $\mathrm{TH}(-)$ neurons in these areas. In parasagittal sections, we report modest expression of $\alpha 6^{*} \mathrm{nAChRs}$ in $\mathrm{TH}(+)$ fibers, presumably 
A

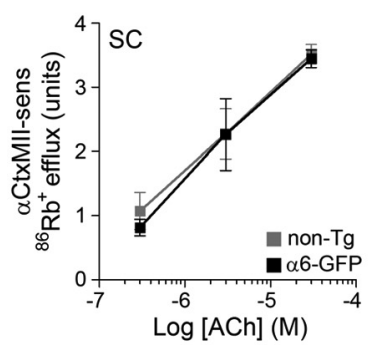

B

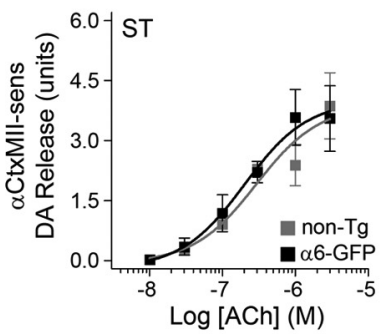

C

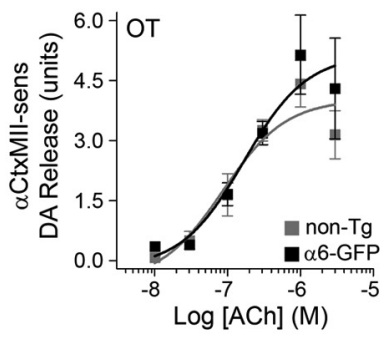

Figure 3. Normal $\alpha 6^{*} \mathrm{nAChR}$ function in $\alpha 6$-GFP transgenic mice. $\boldsymbol{A}$, Normal Rb ${ }^{+}$efflux in $\alpha 6-\mathrm{GFP}$ transgenic mice. A crude synaptosomal pellet was prepared from $\alpha 6$-GFP and their nontransgenic littermates, followed by $\mathrm{Rb}^{+}{ }^{+}$loading and stimulation of $\mathrm{Rb}^{+}$efflux by ACh application. $\mathrm{Rb}^{+}$efflux sensitive to $\alpha$ CtxMII (which includes $\alpha 6$-dependent efflux) is shown for $0.3,3$, and 30 $\mu$ M ACh. $\boldsymbol{B}, \boldsymbol{C}$, Normal DA release in $\alpha 6$-GFP transgenic mice. ST ( $\boldsymbol{B})$ and OT ( $\boldsymbol{C}$ ) were dissected from $\alpha 6$-GFP and their nontransgenic littermates, followed by preparation of synaptosomes. Synaptosomes were loaded with [ ${ }^{3} \mathrm{H}$ ]-DA and stimulated with a range of ACh concentrations $(10,30,100$, and $300 \mathrm{~nm}$ and 1 and $3 \mu \mathrm{m})$ in the presence and absence of $\alpha \mathrm{CtxMII}$. Data were fitted to the Hill equation, and $\alpha$ CtxMll-sensitive concentration response curves are shown for ST (B) and OT (C).

Table 2. Functional measurements of nAChR activity in $\alpha 6$-GFP mice

\begin{tabular}{|c|c|c|}
\hline DA release & Control & $\alpha 6-\mathrm{GFP}$ \\
\hline \multicolumn{3}{|l|}{$\mathrm{ACh}$} \\
\hline ST MIl-res $R_{\max }$ & $12.61 \pm 0.51$ & $12.04 \pm 1.20$ \\
\hline ST MII-res $\mathrm{EC}_{50}$ & $1.01 \pm 0.09$ & $1.12 \pm 0.32$ \\
\hline OT MII-res $R_{\max }$ & $15.86 \pm 0.77$ & $13.63 \pm 0.83$ \\
\hline OT Mll-res $\mathrm{EC}_{50}$ & $0.44 \pm 0.05$ & $0.39 \pm 0.06$ \\
\hline ST MII-sens $R_{\max }$ & $3.34 \pm 0.55$ & $3.93 \pm 0.29$ \\
\hline ST MII-sens EC 50 & $0.18 \pm 0.05$ & $0.23 \pm 0.04$ \\
\hline OT MII-sens $R_{\max }$ & $4.32 \pm 0.52$ & $4.86 \pm 0.75$ \\
\hline OT MII-sens $\mathrm{EC}_{50}$ & $0.11 \pm 0.04$ & $0.19 \pm 0.06$ \\
\hline \multicolumn{3}{|l|}{$\mathrm{K}^{+}$} \\
\hline $\mathrm{ST} \mathrm{K}^{+}(20 \mathrm{~mm})$ & $12.70 \pm 1.29$ & $10.61 \pm 1.24$ \\
\hline $\mathrm{ST} \mathrm{K}^{+}(20 \mathrm{~mm})$ & $14.39 \pm 0.35$ & $12.69 \pm 0.48$ \\
\hline \multicolumn{3}{|l|}{$\mathrm{Rb}^{+}$Efflux (ACh) } \\
\hline SC Mll-res $(0.3 \mu \mathrm{M})$ & $1.08 \pm 0.29$ & $0.82 \pm 0.13$ \\
\hline SC Mll-res $(3 \mu \mathrm{m})$ & $3.04 \pm 0.54$ & $2.26 \pm 0.56$ \\
\hline SC Mll-res $(30 \mu \mathrm{m})$ & $3.52 \pm 0.15$ & $3.45 \pm 0.14$ \\
\hline SC MII-sens $(0.3 \mu \mathrm{M})$ & $0.85 \pm 0.32$ & $0.40 \pm 0.26$ \\
\hline SC Mll-sens ( $3 \mu \mathrm{M})$ & $1.53 \pm 0.51$ & $1.31 \pm 0.43$ \\
\hline SC MII-sens $(30 \mu \mathrm{M})$ & $4.01 \pm 0.77$ & $3.23 \pm 0.74$ \\
\hline
\end{tabular}

For the indicated measurement ( $\mathrm{Rb}^{+}$efflux and $\mathrm{DA}$ release), brain regions were dissected, synaptosomes were prepared, and assays were conducted using $A C h$ as agonist. For $D A$ release, a range of $A C h$ concentrations were tested (or $20 \mathrm{~mm} \mathrm{~K}^{+}$as a positive control), results were fit to the Hill equation, and $R_{\max }$ and/or $\mathrm{EC}_{50}$ values for $\mathrm{ACh}$ were derived and are shown. $\mathrm{K}^{+}$results are total response (units are cpm normalized to baseline). For $\mathrm{Rb}^{+}$efflux, three ACh concentrations $(0.3,3.0$, and $30 \mu \mathrm{m})$ were tested, and peak responses for each concentration are shown. For $\mathrm{Rb}^{+}$efflux and DA release, $\alpha$ CtxMll-sensitive and -resistant activity components are shown. For all experiments, data from groups of $\alpha 6$-GFP and control (nontransgenic) littermate mice were compared. OT, olfactory tubercle; SC, superior colliculus; ST, dorsal striatum. Data (units are cpm normalized to baseline) are mean \pm SEM ( $n=4-6$ mice).

DA axons projecting to striatum and other forebrain targets (Fig. $2 C)$. Staining experiments in nontransgenic control mice (Fig. 2D) demonstrated that punctate $\alpha 6$-GFP expression (Fig. 2C) was not a staining artifact. Axonal $\alpha 6$ staining was more punctate relative to TH staining (Fig. $2 C$ ), suggesting that $\alpha 6^{*} \mathrm{nAChRs}$ were contained within vesicles in axons. Immunoelectron microscopy will be required to determine whether $\alpha 6^{*} \mathrm{nAChRs}$ are expressed on the surface of DA axons, or only within these axons during their transport to DA terminals. Finally, in $\alpha 6$-GFP mice, we found modest $\alpha 6^{*} \mathrm{nAChR}$ expression throughout striatum (Fig. 2E). Similar to DA axons, $\alpha 6^{\star} \mathrm{nAChR}$ expression in striatum was punctate, representing a subset of $\mathrm{TH}(+)$ axons/fibers (Fig. 2E). We found little to no $\alpha 6^{\star}$ expression in $\mathrm{TH}(-)$ structures in striatum, and staining experiments in striatal sections from nontransgenic control mice (Fig. $2 F$ ) ruled out possible staining artifacts as an explanation for our results.
To determine whether $\alpha 6$-GFP nAChRs were distributed like WT $\alpha 6$ nAChRs in the brain, we analyzed $\alpha$ CtxMII-sensitive and -resistant as well as cytisine-sensitive and -resistant epibatidine binding in several brain regions of $\alpha 6$-GFP transgenic mice and their nontransgenic littermates. In cortex, striatum, OT, thalamus, SC, and ventral midbrain, $\alpha$ CtxMII-sensitive and -resistant epibatidine binding were similar between $\alpha 6$ GFP and nontransgenic control mice. No significant differences in $\alpha$ CtxMIIsensitive or -resistant epibatidine binding were noted between $\alpha 6$-GFP and nontransgenic littermates in these brain regions (Table 1). This result was interesting given that $\alpha 6$-GFP transgenic mice possess six ectopic copies of the $\alpha 6$-GFP BAC transgene, and is consistent with previous studies in $\alpha 6 \mathrm{L9}^{\prime} \mathrm{S}$ mice, where multiple copies of the mutant $\alpha 6$ BAC did not result in increased $\alpha 6^{*} \mathrm{nAChRs}$ as measured by radioligand binding (Drenan et al., 2008a).

To determine whether functional responses typically attributed (partially or fully) to $\alpha 6^{\star}$ are altered in $\alpha 6$-GFP mice, we measured ACh-stimulated $\mathrm{nAChR}$ responses in $\mathrm{Rb}^{+}$efflux and DA release assays. We prepared membranes from SC tissue for $\mathrm{Rb}^{+}$efflux, which is a general assay of presynaptic nAChR function (Nashmi et al., 2007). $\alpha 6$-GFP Rb ${ }^{+}$efflux responses were indistinguishable from those of nontransgenic littermates of $\alpha 6$ GFP mice. Both $\alpha$ CtxMII-sensitive (Fig. $3 A$ ) and resistant $\mathrm{Rb}^{+}$ efflux components were similar between these two genotypes at $0.3,3$, and $30 \mu \mathrm{M}$ ACh (Table 2). Next, we prepared synaptosomes from dorsal striatum (ST) and OT and measured AChstimulated DA release. nAChR-dependent DA release was not altered in the $\alpha 6$-GFP mice, as there was no apparent difference between $\alpha 6-\mathrm{GFP}$ and nontransgenic control mice in this assay. For both ST and OT, both the $\alpha$ CtxMII-resistant and -sensitive (Fig. $3 B, C$ ) component of DA release $\left(\mathrm{EC}_{50}\right.$ and $\left.R_{\max }\right)$ were unchanged by expression of $\alpha 6$-GFP nAChRs (Table 2). These nAChR binding and functional experiments suggest that $\alpha 6-\mathrm{GFP}$ $n A C h R s$ are functional, and that there is neither significant overexpression nor defective function of $\alpha 6^{\star}$ nAChRs in $\alpha 6$-GFP BAC transgenic mice.

\section{Presynaptic and postsynaptic $\alpha 6^{\star} \mathrm{nAChR}$ expression in SC}

To further study $\alpha 6^{\star}$ nAChR expression in SC, we imaged $\alpha 6$ GFP expression at high resolution in $\alpha 6$-GFP mice. $\alpha 6$-GFP mice reveal strong $\alpha 6^{\star} \mathrm{nAChR}$ expression in the superficial gray layer of SC (Fig. 4A). In superficial SC (sSC), anti-GFP staining was notably diffuse, presumably indicating dense localization on axons and/or dendrites. Additionally, a population of neuronal somata in SSC and intermediate layers of SC also stained positive for $\alpha 6$-GFP, indicating the presence of several previously unappreciated $\alpha 6^{\star}$ nAChR-expressing cell groups (Fig. $4 A)$. Using anti-NeuN and anti-GFP double-staining, we determined that $13 \pm 2 \%$ of sSC neurons are $\alpha 6(+)$ (Fig. $4 B)$. Doublelabel results with a nuclear stain (Qnuclear) were similar (Fig. 4C; data not shown). The location, size, and dendritic geometry of $\alpha 6(+)$ neurons in sSC resembled sSC "horizontal cells" (Langer and Lund, 1974). Using confocal microscopy, we created a $z$-stack rendering of several $\alpha 6(+)$ neurons in sSC. $\alpha 6(+)$ sSC neurons were generally fusiform in geometry, typically having 
two or three primary dendrites that generally run tangentially to the surface of the colliculus (Fig. 4D).

GAD67, a GABAergic marker, is densely expressed in superficial SC, including a population of GABAergic interneurons (Kaneda et al., 2008a). To further characterize $\alpha 6(+)$ neurons in SC, we stained coronal SC sections with anti-GAD67 antibodies (Fig. 5A1). In sSC, we found modest to strong expression of GAD67 in nearly all $\alpha 6(+)$ neurons (Fig. 5A2, single arrows). $\alpha 6^{\star}$ nAChR expression defined only a subset of GAD67 $(+)$ neurons, however, as several GAD67 $(+)$ neurons in sSC did not express $\alpha 6$-GFP (Fig. 5A2, double arrows). Interestingly, the punctate/diffuse expression pattern seen surrounding $\alpha 6(+)$ neurons in sSC did not colocalize with GAD67, supporting the idea that these puncta are axonal or presynaptic $\alpha 6^{*}$ nAChRs derived from glutamatergic RGC axons. To support this, we stained similar sections with antiVGLUT1 antibodies (Fig. 5B1). VGLUT1 expression in $\mathrm{SSC}$ was modest and punctate, and a substantial fraction of $\alpha 6(+)$ puncta also colocalized with VGLUT1 (Fig. 5B2, single arrows). $\alpha 6$-GFP expression in intermediate SC (iSC) was restricted to a small number of neurons, and did not exhibit a presynaptic expression profile similar to $\mathrm{SSC}$ (Figs. 4A, 5C1). Unlike sSC $\alpha 6(+)$ neurons, iSC $\alpha 6(+)$ neurons were not GABAergic (Fig. 5C2). Together, these results indicate that $\alpha 6^{\star} \mathrm{nAChR}$ subunits exhibit both presynaptic expression in glutamatergic axons and postsynaptic expression in a neuronal subpopulation in both the superficial and intermediate layers of the SC.

\section{Functional expression of $\alpha 6^{*} \mathrm{nAChRs}$ in GABAergic neurons}

To determine whether $\alpha 6^{*} \mathrm{nAChRs}$ are functional in sSC GABAergic neurons, we made whole-cell recordings from sSC neurons in slices from mice expressing hypersensitive $\alpha 6 \mathrm{L9}^{\prime} \mathrm{S}^{*} \mathrm{nAChRs}$. These mutant receptors are 10 - to 100 -fold more sensitive to agonists than WT, allowing for selective activation of $\alpha 6^{*}$ nAChRs (Drenan et al., 2008a). In previous experiments with $\alpha 6 \mathrm{~L}^{\prime} \mathrm{S}^{*} \mathrm{nAChRs}$ expressed in midbrain DA neurons, $1 \mu \mathrm{M}$ nicotine is sufficient to strongly activate an inward current only in neurons from mutant mice (Drenan et al., 2008a). In coronal slices, we locally applied nicotine $(1 \mu \mathrm{M})$ to visually identified voltageclamped neurons in the superficial layer of SC using a drug-filled micropipette and a Picospritzer. In 13 of 21 recorded neurons in $\alpha 6$ L9'S slices, we recorded inward currents (rise time $<100 \mathrm{~ms}$ ) characteristic of nAChR responses (Fig. 6A). These responses were blocked by $\alpha$ CtxMII (100 nM) (Fig. $6 A$ ), suggesting that they were mediated by $\alpha 6^{*}$ nAChRs. In $\alpha 6$ L9'S neurons with inward responses, the average peak amplitude of the nicotine-
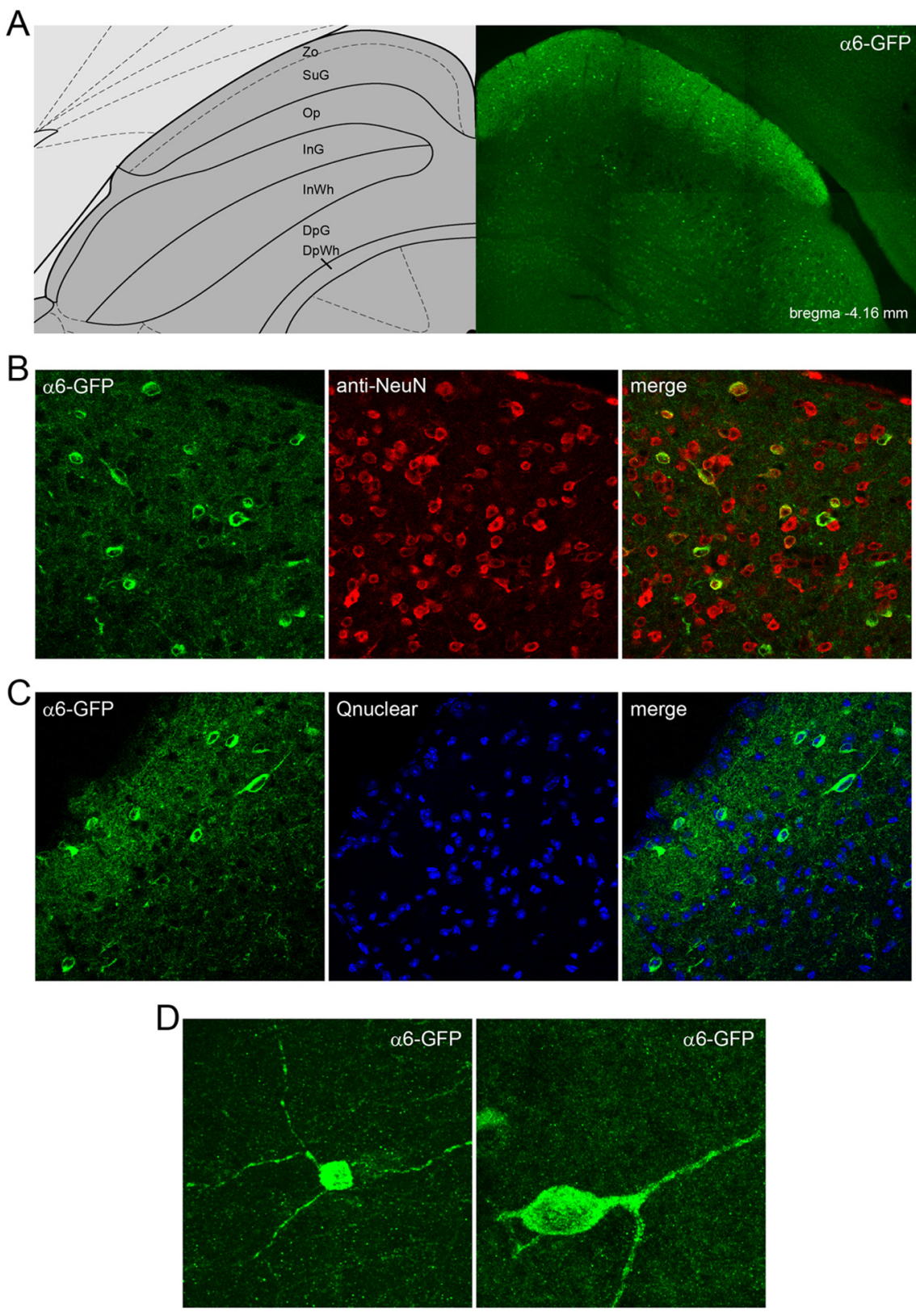

Figure 4. $\quad \alpha 6^{*} \mathrm{nAChR}$ expression in $\mathrm{SSC}$ neurons. $A, \alpha 6^{*} \mathrm{nAChR}$ expression in a GFP-stained coronal section (bregma -4.16 $\mathrm{mm}$ ) from $\alpha 6$-GFP transgenic mice is shown next to a diagram of the SC (Paxinos and Franklin, 2001). $\alpha 6^{*} \mathrm{nAChR}$ expression is limited to the zonal layer (Zo), the superficial gray layer (SuG), and intermediate gray layer (InG). B, C, $\alpha 6^{*}$ nAChRs are expressed in a subset of neurons in SSC. In $\boldsymbol{B}$, SC coronal sections were double stained with anti-GFP and anti-NeuN antibodies, followed by laser scanning confocal imaging. Individual GFP and NeuN channels and a merge micrograph are shown, at $60 \times$ magnification. In C, similar sections were double stained with anti-GFP antibodies and a nuclear stain, followed by confocal imaging as in $\boldsymbol{B}, \boldsymbol{D}$, Z-stack rendering of $\alpha 6(+)$ neurons in sSC. Two $\alpha 6(+)$ neurons in sSC were imaged with confocal microscopy and a 3D volume render of the cell body and its processes was created following serial Z-sectioning through the neuron. 0p, optic nerve layer; InWh, intermediate white layer; DpG, deep gray layer; DpWh, deep white layer.

induced currents was $-47 \pm 5$ pA (Fig. $6 B$ ). Responses to $1 \mu \mathrm{M}$ nicotine in these neurons were specific to the $\alpha 6 \mathrm{~L} 9^{\prime} \mathrm{S}$ genotype, as we recorded no detectable responses to $1 \mu \mathrm{M}$ nicotine in nontransgenic control slices (Fig. 6B, C). Higher concentrations of nicotine $(100 \mu \mathrm{M})$ were required to elicit similar responses in sSC neurons from control slices (Fig. 6C). Responses to $1 \mu \mathrm{M}$ nicotine in the remaining eight neurons from L9'S slices were either nonexistent or small but complex responses with inward and outward components (data not shown). We recorded $\alpha 6^{\star}$ nAChRmediated responses in a higher fraction of recorded neurons in 

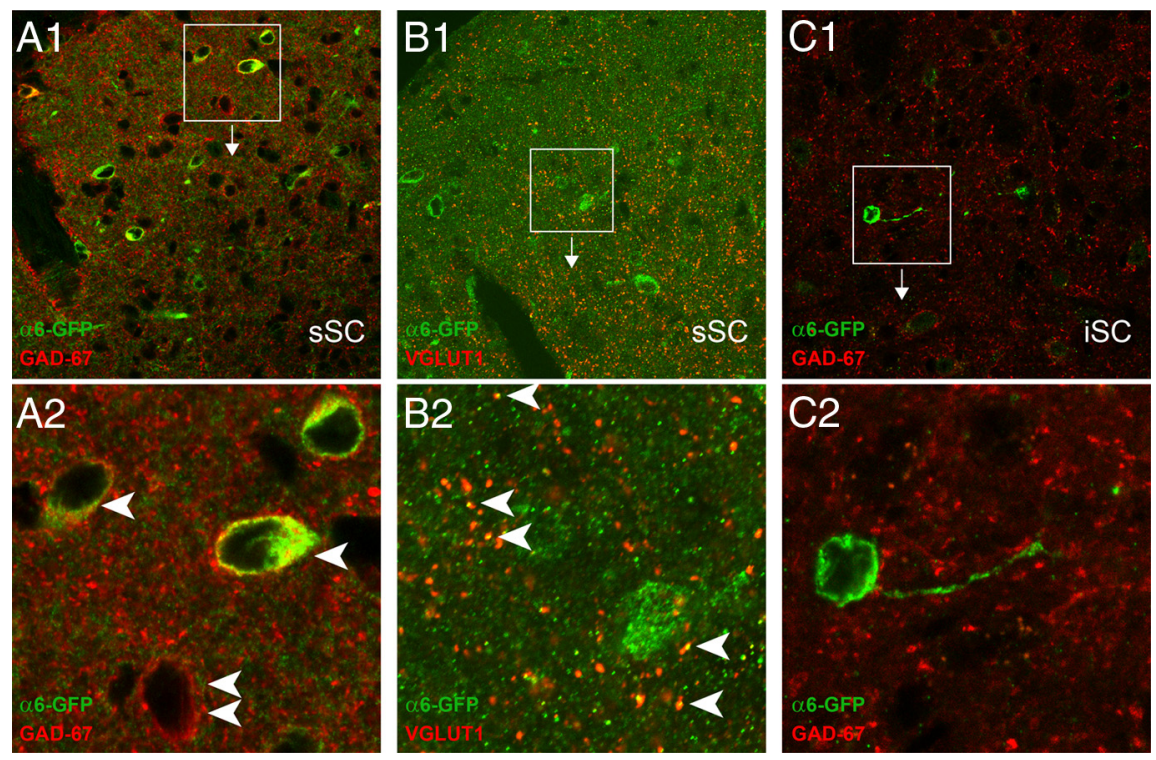

Figure 5. Transmitter phenotypes of $\alpha 6(+)$ neurons in SC. $A, \alpha 6^{*}$ nAChRs are expressed in GABAergic neurons in SSC. Coronal sections from $\alpha 6$-GFP transgenic mice containing sSC were double stained with anti-GFP and anti-GAD67 antibodies, followed by confocal microscopy. $\mathbf{A 2}$, Represents the boxed area in the $\boldsymbol{A} \mathbf{1}$ image. Single white arrows indicate cells coexpressing $\alpha 6^{*} \mathrm{nAChRs}$ and GAD67, whereas double white arrows indicate cells expressing only GAD67.B, $\alpha 6^{*} \mathrm{nAChRs}$ are also expressed in glutamatergic fibers in $\mathrm{SSC}$. Coronal sections from $\alpha 6$-GFP transgenic mice containing $\mathrm{SSC}$ were double stained with anti-GFP and anti-VGLUT1 antibodies, followed by confocal microscopy. $\boldsymbol{B} 2$, Represents the boxed area in the $\boldsymbol{B} \mathbf{1}$ image. White arrows indicate colocalized VGLUT1 and $\alpha 6^{*}$ nAChRs. C, iSC $\alpha 6(+)$ neurons are not GABAergic. Coronal sections from $\alpha 6$-GFP transgenic mice containing iSC were double stained with anti-GFP and anti-GAD67 antibodies, followed by confocal microscopy. (2, Represents the boxed area in the $\mathbf{C}$ image.

$\alpha 6 \mathrm{~L} 9^{\prime} \mathrm{S}$ mice than we expected based on fluorescent neurons in $\alpha 6$-GFP mice. We often selected larger cells when searching for healthy neurons from which to record in sSC, and $\alpha 6 \mathrm{nAChR}$ subunits may be selectively present in larger $\mathrm{SSC}$ neurons. Alternatively, $\alpha 6(+)$ neurons in sSC may be intrinsically healthier than $\alpha 6(-)$ sSC cells, allowing them to preferentially survive the slicing procedure.

To further characterize $\alpha 6(+)$ neurons in SSC, we recorded several voltage-clamp and current-clamp responses in these cells. $\alpha 6(+)$ sSC neurons had an average resting membrane potential of $-56 \pm 4 \mathrm{mV}$, and typically did not fire spontaneous action potentials. In response to depolarizing current injections of +20 to $+40 \mathrm{pA}, \alpha 6(+)$ neurons fired action potentials at $20-40 \mathrm{~Hz}$ (Fig. $6 \mathrm{D}$ ). In response to hyperpolarizing current injections, typical $\alpha 6(+)$ sSC neurons responded with a small but distinct and rapid adaptation in its membrane potential (Fig. 6D). This voltage "sag" is characteristic of expression of $I_{h}$ currents. To determine whether these neurons express $I_{h}$ currents, we voltage clamped $\alpha 6(+)$ neurons and recorded current responses following hyperpolarizing voltage steps. $\alpha 6(+)$ sSC neurons did express $I_{h}$ currents (Fig. $6 E$ ), with a maximum hyperpolarization-activated current of $-31 \pm 6 \mathrm{pA}$ during hyperpolarization to $-120 \mathrm{mV}$ (Fig. 6 F).

$\alpha 6$-dependent responses in $\alpha 6(+)$ neurons could be due to activation of somatodendritic nAChRs and cation influx through nAChRs, or they may result from indirect activation of cationic conductances. In our recording conditions, we voltage clamp sSC neurons at $-60 \mathrm{mV}$, and $E_{\mathrm{Cl}}$ is $\sim-83 \mathrm{mV}$. As a result, $\mathrm{GABA}_{\mathrm{A}}$ receptor activation is unlikely to play a major role in generating $\alpha 6$-dependent inward current responses. Furthermore, NMDA-dependent currents are an unlikely contributor, as these channels are largely blocked by intracellular $\mathrm{Mg}^{2+}$ at $-60 \mathrm{mV}$. To determine whether inward current responses seen in $\alpha 6(+)$ neurons in slices from $\alpha 6 \mathrm{~L}^{\prime} \mathrm{S}$ mice are mediated by postsynaptic versus presynaptic nAChRs, we treated slices with 6-cyano-7nitroquinoxaline-2,3-dione (CNQX; 20 $\mu \mathrm{M})$ to inhibit fast excitatory glutamatergic transmission. In the presence of CNQX, the amplitude and duration of nicotine-evoked currents were largely unchanged relative to control, suggesting that presynaptic AMPA receptors do not play a role in generating inward currents in $\alpha 6(+)$ neurons (Fig. $7 A$, upper and middle trace). Next, we blocked voltagegated $\mathrm{Na}^{+}$channels with TTX $(0.5 \mu \mathrm{M})$ to eliminate synaptic activity requiring action potentials. In the presence of CNQX and TTX, inward current responses in $\alpha 6(+)$ neurons remained largely unaltered, again suggesting a direct cation influx through nAChRs is responsible for the inward current responses seen in our slice preparations (Fig. 7A, bottom trace). $\alpha 6(+)$ neurons in sSC were often characterized by a tonic membrane conductance that was apparent when voltageclamped at $-60 \mathrm{mV}$ (Fig. $7 B$, upper trace). This enhanced membrane conductance was absent in $\alpha 6(-)$ sSC neurons from $\alpha 6$ L9'S mice (Fig. 7B, middle trace), and was similarly absent in sSC neurons from nontransgenic slices expressing inward nAChR-mediated currents (Fig. 7B, bottom trace). Indeed, in $\alpha 6 \mathrm{~L}^{\prime}$ 'S sSC neurons, there was an increased noise in the voltage-clamp record in $\alpha 6(+)$ neurons compared with $\alpha 6(-)$ neurons (Fig. 7C). These currents lacked the waveform of typical EPSCs or IPSCs that are generated via point-to-point synaptic transmission mechanisms, and were suggestive of volume transmission via $\mathrm{ACh}$. These tonic membrane currents were largely unaffected by treatment of slices with CNQX and TTX (Fig. 7D, upper and middle trace). Tonic membrane currents in SSC $\alpha 6(+)$ neurons were completely blocked, however, by $\alpha$ CtxMII (Fig. 7D, bottom trace). Bath application of hemicholinium-3 (HC-3; $50 \mu \mathrm{M}$ ), which blocks choline uptake into cholinergic presynaptic terminals and results in elimination of ACh release, was sufficient to eliminate tonic membrane currents in sSC $\alpha 6(+)$ neurons (Fig. $7 E ; n=2$, representative results shown). These results in $\alpha 6 \mathrm{~L}^{\prime} \mathrm{S}$ slices, where $\alpha 6^{*} \mathrm{nAChR}$ coupling to locally released ACh is exaggerated, suggest that WT $\alpha 6^{*}$ nAChRs in SSC neurons are strongly activated by tonic or phasic ACh. $\alpha 6^{*}$ nAChR activation by ACh may increase GABA release in $\mathrm{SSC}$ to influence processing of visual information.

To confirm in vivo that $\alpha 6^{\star} \mathrm{nAChRs}$ are expressed in sSC neurons, we measured c-Fos induction in this brain area following intraperitoneal injections of nicotine. $\alpha 6 \mathrm{~L} 9^{\prime} \mathrm{S}$ and nontransgenic control littermate mice were injected with saline, or a dose of nicotine $(0.15 \mathrm{mg} / \mathrm{kg}$; i.p. $)$ that selectively induces a behavioral effect in L9'S mice but not control mice (Drenan et al., 2008a, 2010). At this dose, nicotine robustly induced c-Fos expression in $\alpha 6$ L9'S sSC, which was not the case in nontransgenic control mice (Fig. 8A). Saline injections in nontransgenic control mice and L9'S mice resulted in similar levels of c-Fos expression compared with nontransgenic control mice injected with nicotine (Fig. 8A). We sampled and quantified c-Fos expression at several 
points across the anterior to posterior extent of the sSC. c-Fos induction was significantly higher within the $\alpha 6$ L9'S line when we compared saline versus nicotine $(0.15 \mathrm{mg} / \mathrm{kg})\left(\alpha 6 \mathrm{~L} 9^{\prime} \mathrm{S}\right.$, nicotine: $12.3 \times$ $10^{-4} \mathrm{c}-\mathrm{Fos}(+)$ cells $/ \mu \mathrm{m}^{2} ; \alpha 6$ L9'S, saline: $7.1 \times 10^{-4} \mathrm{c}-\mathrm{Fos}(+)$ cells $/ \mu \mathrm{m}^{2} ; p<$ 0.0001 ) (Fig. $8 B$ ). There was no significant difference in c-Fos induction/expression within nontransgenic control mice when we compared saline versus nicotine (nontransgenic, nicotine: $5.7 \times 10^{-4}$ c-Fos $(+)$ cells $/ \mu \mathrm{m}^{2}$; nontransgenic, saline: $6.0 \times 10^{-4} \mathrm{c}$-Fos $(+)$ cells $/ \mu \mathrm{m}^{2} ; p=$ 0.68 ) (Fig. 8 B). Together with our electrophysiology results from $\alpha 6 \mathrm{~L}^{\prime} \mathrm{S}$ mice, these results support the idea that $\alpha 6^{*}$ nAChRs function in sSC, and that activation of these nAChRs can influence neuronal excitability.

\section{Discussion}

Previous pioneering studies on $\mathrm{nAChR}$ expression in visual and DAergic areas have often relied on radiolabeled probes such as $\alpha$ CtxMII and epibatidine (Whiteaker et al., 2000a,b, 2002). Because $\alpha$ CtxMII does not discriminate well between $\alpha 6^{*}$ nAChRs and $\alpha 3^{*}$ nAChRs, there remain uncertainties about which nAChR subtypes are most important without concomitant use of other tools that help amplify or isolate the function of particular nAChRs. Here, we have used a new transgenic reporter mouse expressing GFP-labeled $\alpha 6$ nAChR subunits to map $\alpha 6^{*} \mathrm{nAChR}$ expression at high resolution. We demonstrate conclusively that $\alpha 6^{*}$ nAChR subunits exhibit a specific expression pattern in the mouse visual system, including expression in a subset of RGCs, a striated, presynaptic expression pattern in visual thalamus, and dense presynaptic and postsynaptic expression in superficial and intermediate/deep layers of SC. $\alpha 6^{*}$ nAChRs, as we and others have previously suggested (Le Novère et al., 1996; Léna et al., 1999; Azam et al., 2002; Drenan et al., 2008a), are specifically expressed in cell bodies, axons, and presynaptic terminals of catecholamine-producing neurons in the ventral midbrain (SNc/VTA) and dorsal pons (LC).

Our data demonstrating expression of $\alpha 6^{*} \mathrm{nAChRs}$ in retinal cells and retinal axons are consistent with previous findings, including mRNA in situ hybridization studies (Moretti et al., 2004), eye enucleation experiments (Gotti et al., 2005), and studies on $\alpha 6 \mathrm{KO}$ mice (Champtiaux et al., 2002; Gotti et al., 2005). Our $\alpha 6^{*}$ $\mathrm{nAChR}$ expression data in the retina, where only $\sim 52 \%$ of GCL neurons (presumptive RGCs) express $\alpha 6^{*}$ nAChRs, suggests that $\alpha 6^{\star} \mathrm{nAChRs}$ perform a specific function(s) in one or more subsets of RGCs, rather than a uniform modulation of RGCs. This is consistent with recent evidence detailing numerous subpopulations of RGCs, each with unique features (Kim et al., 2010; Kay et al., 2011). Direction-selective RGCs express several nAChR subtypes (Strang et al., 2007), and $\alpha 6^{\star}$ nAChRs may be expressed in some or all of these cells. We did not find significant expression of $\alpha 6$ subunits in putative RGC dendrites in the inner plexiform
B

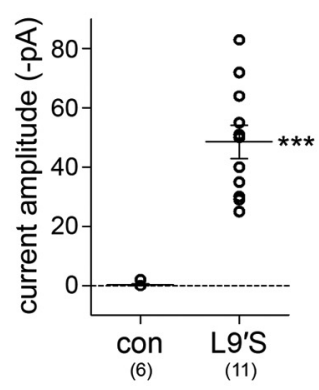

C

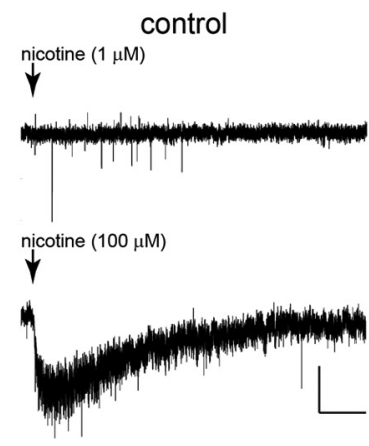

$\mathrm{F}$

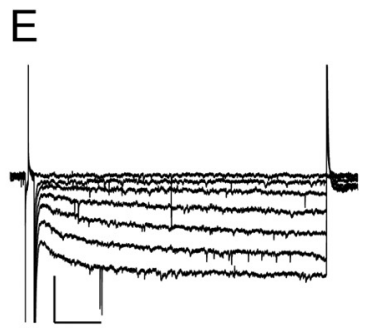

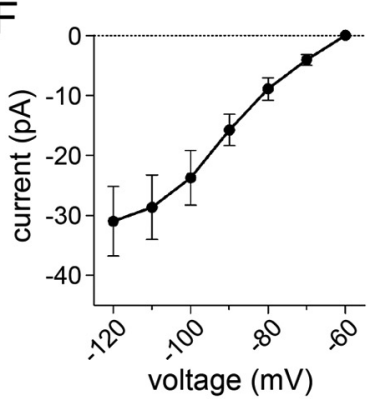

Figure 6. $\alpha 6^{*} \mathrm{nAChRsfunction} \mathrm{in} \mathrm{S} S \mathrm{C}$ neurons. $\boldsymbol{A}, \alpha 6$-dependent nicotinic currents in sSC neurons. Coronal slices were prepared nontransgenic control slices did not respond to $1 \mu \mathrm{m}$ nicotine but responded with typical nAChR inward currents when stimulated

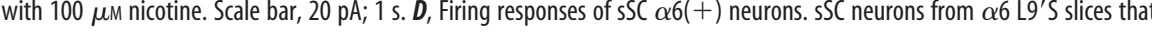
studied $\alpha 6(+)$ sSC neurons is indicated. Scale bar, $30 \mathrm{mV} ; 400 \mathrm{~ms}$. $\boldsymbol{E}$, $I_{h}$ current in $\alpha 6(+) \mathrm{s} S \mathrm{C}$ neurons. The same group of cells in $\mathbf{D}$ were held in voltage-clamp mode at $-60 \mathrm{mV}$, and membrane currents were recorded during hyperpolarizing 等, $S$ cale bar, $40 \mathrm{pA} ; 300 \mathrm{~ms}$. $\boldsymbol{F}$, Current-voltage relations for $I_{h}$ currents shown in $\boldsymbol{E}$. Peak current changes were measured immediately before the end of each hyperpolarizing pulse. Data are mean \pm SEM. ${ }^{* * *} p<0.0001$.

layer (Fig. 1C). Together with strong expression in optic nerve axons, these data suggest that retinal-derived $\alpha 6^{\star}$ nAChRs may be selectively targeted to axons and/or presynaptic terminals. Dense yet specific expression of $\alpha 6^{\star}$ nAChRs on a subset of retinal axons and/or glutamatergic presynaptic terminals in retinorecipient areas suggests that $\alpha 6^{\star} \mathrm{nAChRs}$ mediate cholinergic sensitization of specific visual signals, such as subsecond changes in contrast or the appearance of novel objects in the visual field.

Previous studies using [ $\left.{ }^{125} \mathrm{I}\right]-\alpha \mathrm{CtxMII}$ to detail $\alpha 3 / \alpha 6 \mathrm{nAChR}$ binding and expression in retinorecipient structures such as $\mathrm{dLGN}$ and SC were not-due to the inherently low resolution provided by radiolabeled probes-able to resolve somatic expression of $\alpha 6$ versus dense localization in presynaptic structures. Our data using GFP-labeled $\alpha 6$ nAChR subunits coupled with high-resolution confocal microscopy confirm that $\alpha 6^{\star}$ nAChRs are expressed not only in glutamatergic RGC axons (Fig. 5B), but in a particular cell population in SSC (Fig. 4). A previous report indicated that eye enucleation reduced $\alpha 6^{*} \mathrm{nAChRs}$ in SC by $91 \%$ and $\beta 3^{\star}$ nAChRs by $92 \%$ (Gotti et al., 2005). The residual $\alpha 6^{*} \mathrm{nAChRs}$ in these experiments could correspond to the postsynaptic sSC $\alpha 6^{*} \mathrm{nAChRs}$ we describe here. The pattern of somatic $\alpha 6^{*} \mathrm{nAChR}$ expression in sSC and iSC is nearly identical to mRNA in situ hybridization data available for $\alpha 6^{*}$ and $\beta 3^{*}$ 


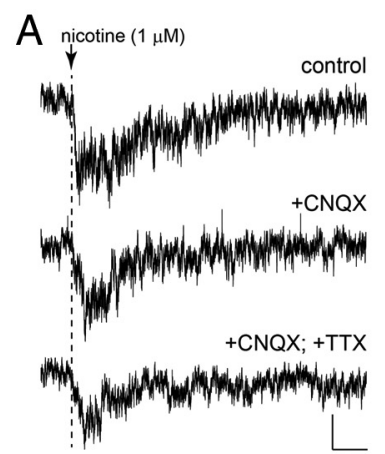

B

C

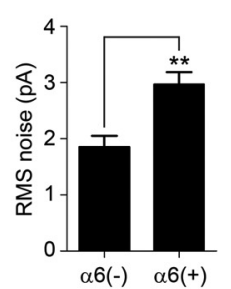

D
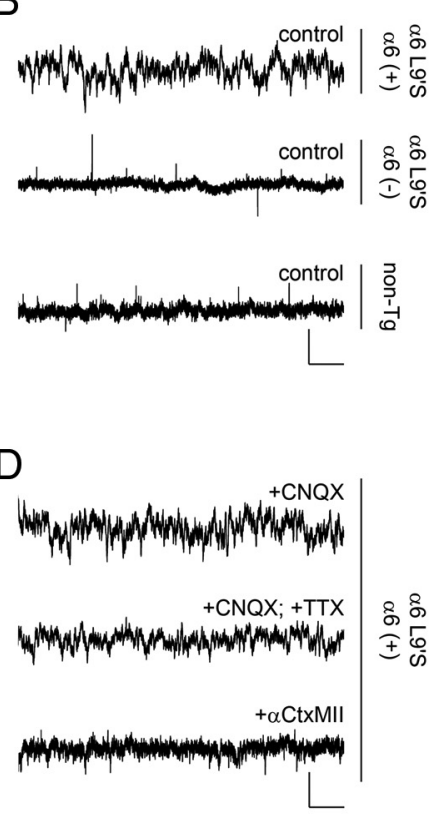

E

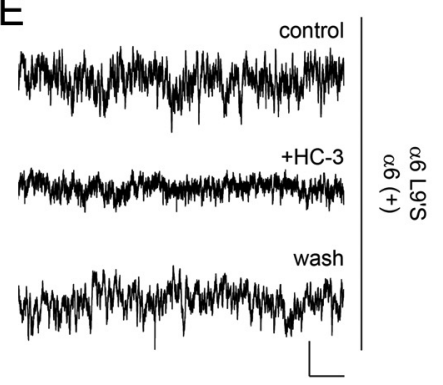

Figure 7. $\alpha 6^{*}$ nAChRs in $\mathrm{SSC}$ neurons are postsynaptic and respond to ambient ACh. $\boldsymbol{A}$, Whole-cell nAChR responses in $\alpha 6(+)$ neurons are postsynaptic. Responses to $1 \mu \mathrm{m}$ nicotine in $\alpha 6 \mathrm{~L}$ ' $\mathrm{S}$ SSC neurons were tested for sensitivity to CNQX (20 $\mu \mathrm{m})$ and CNQX plus TTX $(0.5 \mu \mathrm{M})$. Scale bar, $20 \mathrm{pA} ; 2 \mathrm{~s}$. B. Holding currents in $\alpha 6(+) \mathrm{sSC}$ neurons exhibits greater membrane conductance fluctuations. SSC $\alpha 6(+), \alpha 6(-)$, and nontransgenic neurons responding to 100 $\mu \mathrm{m}$ nicotine were recorded in voltage-clamp mode. Representative voltage-clamp records showing membrane conductance fluctuations in the indicated cell type are shown. Scale bar, 6 $\mathrm{pA} ; 600 \mathrm{~ms}$. C, Quantification of membrane conductance fluctuations in $\alpha 6 \mathrm{~L} 9^{\prime} \mathrm{S} \alpha 6(+)$ and $\alpha 6(-)$ sSC neurons. Average root mean square noise for voltage-clamp membrane currents recorded in SSC neurons identified as $\alpha 6(+)$ or $\alpha 6(-)$ is shown. Data are mean \pm SEM. A Student's $t$ test was used to compare $\alpha 6(-)$ and $\alpha 6(+)$ RMS noise. ${ }^{* *} p<0.01$. D, Increased membrane conductance fluctuations in $\alpha 6(+) \mathrm{sSC}$ neurons is blocked by $\alpha$ CtxMII. Identified $\alpha 6(+)$ sSC neurons in $\alpha 6 \mathrm{Lg}$ 'S slices were recorded in voltage-clamp mode, and membrane conductance fluctuations were observed in the presence of CNQX, CNQX plus TTX, or $\alpha$ CtxMII $(100 \mathrm{~nm})$. Scale bar, $6 \mathrm{pA} ; 600 \mathrm{~ms}$. E, Membrane conductance fluctuations in a6 (+) sSC neurons are eliminated by inhibition of ACh release. $\alpha 6(+) s S C$ neurons were recorded as in $\boldsymbol{D}$, and membrane conductance fluctuations were observed in the presence of $\mathrm{HC}-3(50 \mu \mathrm{m})$ and after drug washout. A representative experiment $(n=2)$ is shown.

nAChR subunits from the Allen Brain Atlas (www.brain-map. org). sSC GABAergic $\alpha 6(+)$ neurons are fusiform in shape with two or three primary dendrites (Fig. 4D), were found within 200 $\mu \mathrm{m}$ of the surface of the colliculus, and were characterized by a modest $I_{h}$ current (Fig. 6E,F). These characteristics correspond best to sSC horizontal cells (Langer and Lund, 1974; Endo et al., 2003, 2008), which are GABAergic interneurons. This suggests that $\alpha 6^{\star} \mathrm{nAChR}$ activity may be important for shaping transmission of visual information as it proceeds from the optic nerve to the output layers of the SC. A previous report demonstrated agonist-evoked inward and outward currents in sSC neurons that

A
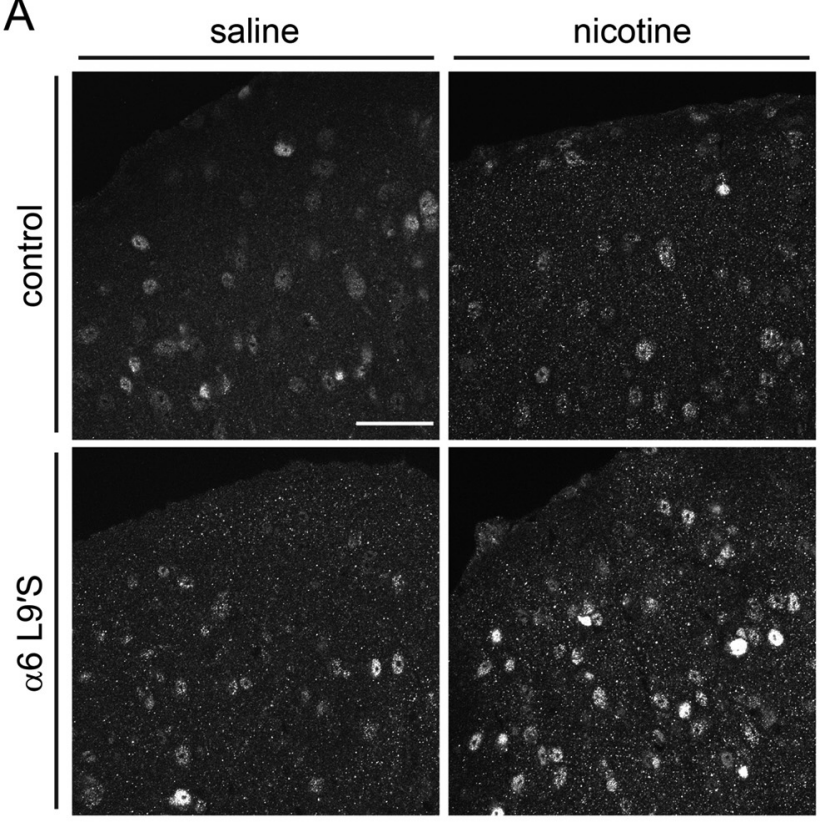

B

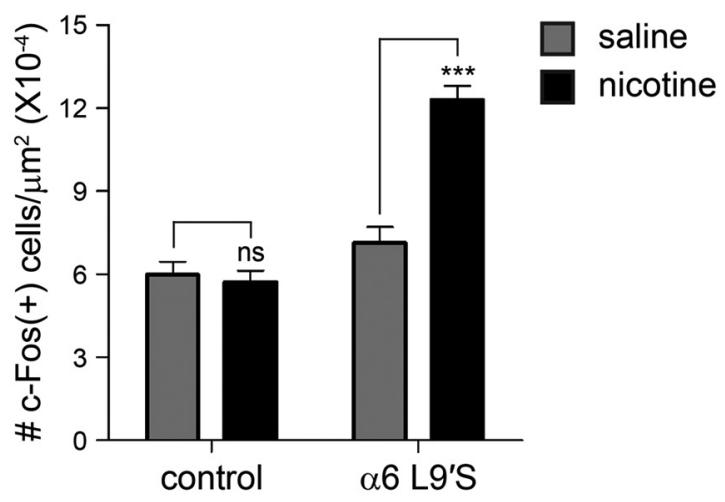

Figure 8. Activation of $\mathrm{SSC} \alpha 6^{*} \mathrm{nAChRs}$ in vivo. A, Induction of c-Fos expression following nicotine injections in control and $\alpha 6 \mathrm{~L} 9^{\prime} \mathrm{S}$ mice. Mice of the indicated genotype were injected with saline or nicotine $(0.15 \mathrm{mg} / \mathrm{kg}$; i.p.), perfused, and brains were removed and sectioned for anti-c-Fos staining. Representative sSC-containing brain sections stained with anti-c-Fos antibodies are shown for control and $\alpha 6$ L9'S mice. Scale bar, $50 \mu \mathrm{m}$. B, Quantification of c-Fos staining. Images ( $n=10$ for each genotype) of c-Fos-stained sSC brain sections, sampled from multiple bregma levels, were analyzed for the number of c-Fos immunoreactive cells per square micrometer of brain tissue. Results from saline and nicotine injections for control and $\alpha 6 \mathrm{~L} 9^{\prime} \mathrm{S}$ mice are plotted. Data are mean \pm SEM. A Student's $t$ test was used to compare saline versus nicotine within mouse lines; ${ }^{* * *} p<0.0001$.

were attributed to several nAChR subtypes. Putative horizontal cells in sSC often had $\alpha$ CtxMII-sensitive components to their inward current responses, implicating $\alpha 6$ and/or $\alpha 3$ nAChRs (Endo et al., 2005). Outward currents in other sSC neurons, which were partially mediated by presynaptic facilitation of GABA release, were also blocked by $\alpha$ CtxMII (Endo et al., 2005). These results, together with our data, suggest an important role for $\alpha 6^{*} \mathrm{nAChRs}$ in shaping GABAergic transmission in sSC.

$\alpha 4 \beta 2^{\star}$ and $\alpha 6 \beta 2^{\star}$ nAChRs are critical regulators of nicotinic cholinergic transmission in the DA system, but is there a meaningful connection between DA transmission and visual processing? In awake behaving cats, Horvitz and et al. (1997) reported the production of phasic DA neuron firing in response to nonconditioned visual stimulation. The phasic responses in DA neu- 
rons occurred too rapidly ( $\sim 50-100 \mathrm{~ms})$ to involve significant processing by visual cortex, suggesting a subcortical route for visual information to reach DA neurons. More recently, a direct projection from intermediate and deep layers of SC to ventral midbrain DA neurons has been described that likely mediates this rapid response in DA neurons (Comoli et al., 2003; May et al., 2009) and in downstream structures such as striatum (Dommett et al., 2005). In addition to their roles encoding motivation/value and salience, DA neurons also respond to sensory events not directly connected to reward or aversive experiences (Chiodo et al., 1980; Steinfels et al., 1983; Strecker and Jacobs, 1985; Horvitz, 2000; Horvitz et al., 1997). These responses occur at short latency $(\sim 50-100 \mathrm{~ms})$ and are strongest when the triggering stimulus is unexpected (Schultz and Romo, 1990). The latency of these sensory-evoked responses in DA neurons, along with the fact that they preferentially respond to novel cues, is highly consistent with their being generated by the SC (Bromberg-Martin et al., 2010). It is interesting that $\alpha 6^{*} \mathrm{nAChRs}$ are not only expressed in presynaptic and postsynaptic structures in sSC, but also in sparse nonGABAergic cell bodies in iSC (Fig. 5C). Intermediate and deep layers of SC receive input from and provide feedback to superficial SC (Katsuta and Isa, 2003; Endo et al., 2008; Kaneda et al., 2008b; Phongphanphanee et al., 2011). These $\alpha 6(+)$ neurons may be among those that project directly to midbrain DA neurons, and further studies are required to elucidate their function.

In light of this role of the SC in triggering DA neuron phasic firing in response to an unexpected visual stimulus, it is interesting that $\alpha 6^{*} \mathrm{nAChR}$ expression is enriched in this pathway. Expression of $\alpha 6^{*}$ nAChRs in RGCs, the optic nerve, visual thalamus, the SC, DA neuron cell bodies, DA axons, and DA presynaptic terminals largely encompasses $\alpha 6^{*} \mathrm{nAChR}$ expression in the mammalian brain. Together, our data along with previous findings suggest that $\alpha 6^{\star}$ nAChRs may be uniquely suited to mediate cholinergic sensitization of brain pathways important for recognizing and responding to unexpected and potentially important sensory experiences. Although other nAChR subunits are also expressed in some of these brain areas (Moretti et al., 2004; Endo et al., 2005; Gotti et al., 2005; Cox et al., 2008), this role for $\alpha 6^{*}$ nAChRs contrasts with the action of $\alpha 4$ (non$\alpha 6) \beta 2^{\star}$ nAChRs, which are more widely expressed and may play a more general — though still crucial—role in cholinergic sensitization of neural circuits. What advantage do $\alpha 6 \mathrm{nAChR}$ subunits provide over nAChRs already containing $\alpha 4$ and $\beta 2$ subunits? $\alpha 6^{*}$ nAChRs are among those with the highest sensitivity (Salminen et al., 2007), which could reflect the particular evolutionary importance of reliably alerting and responding to novel, potentially rewarding events in the environment. Additional studies are required to fully explore the role $\alpha 6^{\star} \mathrm{nAChRs}$ at the intersection of visual and DAergic systems.

\section{References}

Azam L, McIntosh JM (2006) Characterization of nicotinic acetylcholine receptors that modulate nicotine-evoked $\left[{ }^{3} \mathrm{H}\right]$ norepinephrine release from mouse hippocampal synaptosomes. Mol Pharmacol 70:967-976.

Azam L, Winzer-Serhan UH, Chen Y, Leslie FM (2002) Expression of neuronal nicotinic acetylcholine receptor subunit mRNAs within midbrain dopamine neurons. J Comp Neurol 444:260-274.

Azam L, Maskos U, Changeux JP, Dowell CD, Christensen S, De Biasi M, McIntosh JM (2010) $\alpha$-Conotoxin BuIA[T5A;P6O]: a novel ligand that discriminates between $\alpha 6 \beta 4$ and $\alpha 6 \beta 2$ nicotinic acetylcholine receptors and blocks nicotine-stimulated norepinephrine release. FASEB J 24:5113-5123.

Ballester M, Castelló A, Ibáñez E, Sánchez A, Folch JM (2004) Real-time quantitative PCR-based system for determining transgene copy number in transgenic animals. Biotechniques 37:610-613.
Briggs CA, Gubbins EJ, Marks MJ, Putman CB, Thimmapaya R, Meyer MD, Surowy CS (2006) Untranslated region-dependent exclusive expression of high-sensitivity subforms of $\alpha 4 \beta 2$ and $\alpha 3 \beta 2$ nicotinic acetylcholine receptors. Mol Pharmacol 70:227-240.

Bromberg-Martin ES, Matsumoto M, Hikosaka O (2010) Dopamine in motivational control: rewarding, aversive, and alerting. Neuron 68:815-834.

Champtiaux N, Han ZY, Bessis A, Rossi FM, Zoli M, Marubio L, McIntosh JM, Changeux JP (2002) Distribution and pharmacology of $\alpha 6$ containing nicotinic acetylcholine receptors analyzed with mutant mice. J Neurosci 22:1208-1217.

Champtiaux N, Gotti C, Cordero-Erausquin M, David DJ, Przybylski C, Léna C, Clementi F, Moretti M, Rossi FM, Le Novère N, McIntosh JM, Gardier AM, Changeux JP (2003) Subunit composition of functional nicotinic receptors in dopaminergic neurons investigated with knock-out mice. J Neurosci 23:7820-7829.

Chiodo LA, Antelman SM, Caggiula AR, Lineberry CG (1980) Sensory stimuli alter the discharge rate of dopamine (DA) neurons: evidence for two functional types of DA cells in the substantia nigra. Brain Res 189:544-549.

Cohen BN, Mackey ED, Grady SR, McKinney S, Patzlaff NE, Wageman CR, McIntosh JM, Marks MJ, Lester HA, Drenan RM (2012) Nicotinic cholinergic mechanisms causing elevated dopamine release and abnormal locomotor behavior. Neuroscience 200:31-41.

Comoli E, Coizet V, Boyes J, Bolam JP, Canteras NS, Quirk RH, Overton PG, Redgrave P (2003) A direct projection from superior colliculus to substantia nigra for detecting salient visual events. Nat Neurosci 6:974-980.

Cox BC, Marritt AM, Perry DC, Kellar KJ (2008) Transport of multiple nicotinic acetylcholine receptors in the rat optic nerve: high densities of receptors containing $\alpha 6$ and $\beta 3$ subunits. J Neurochem 105:1924-1938.

Dommett E, Coizet V, Blaha CD, Martindale J, Lefebvre V, Walton N, Mayhew JE, Overton PG, Redgrave P (2005) How visual stimuli activate dopaminergic neurons at short latency. Science 307:1476-1479.

Drenan RM, Grady SR, Whiteaker P, McClure-Begley T, McKinney S, Miwa JM, Bupp S, Heintz N, McIntosh JM, Bencherif M, Marks MJ, Lester HA (2008a) In vivo activation of midbrain dopamine neurons via sensitized, high-affinity $\alpha 6^{\star}$ nicotinic acetylcholine receptors. Neuron 60:123-136.

Drenan RM, Nashmi R, Imoukhuede P, Just H, McKinney S, Lester HA (2008b) Subcellular trafficking, pentameric assembly, and subunit stoichiometry of neuronal nicotinic acetylcholine receptors containing fluorescently labeled $\alpha 6$ and $\beta 3$ subunits. Mol Pharmacol 73:27-41.

Drenan RM, Grady SR, Steele AD, McKinney S, Patzlaff NE, McIntosh JM, Marks MJ, Miwa JM, Lester HA (2010) Cholinergic modulation of locomotion and striatal dopamine release is mediated by $\alpha 6 \alpha 4^{\star}$ nicotinic acetylcholine receptors. J Neurosci 30:9877-9889.

Endo T, Yanagawa Y, Obata K, Isa T (2003) Characteristics of GABAergic neurons in the superficial superior colliculus in mice. Neurosci Lett 346:81-84.

Endo T, Yanagawa Y, Obata K, Isa T (2005) Nicotinic acetylcholine receptor subtypes involved in facilitation of GABAergic inhibition in mouse superficial superior colliculus. J Neurophysiol 94:3893-3902.

Endo T, Tarusawa E, Notomi T, Kaneda K, Hirabayashi M, Shigemoto R, Isa T (2008) Dendritic Ih ensures high-fidelity dendritic spike responses of motion-sensitive neurons in rat superior colliculus. J Neurophysiol 99:2066-2076.

Exley R, Maubourguet N, David V, Eddine R, Evrard A, Pons S, Marti F, Threlfell S, Cazala P, McIntosh JM, Changeux JP, Maskos U, Cragg SJ, Faure P (2011) Distinct contributions of nicotinic acetylcholine receptor subunit $\alpha 4$ and subunit $\alpha 6$ to the reinforcing effects of nicotine. Proc Natl Acad Sci U S A 108:7577-7582.

Gotti C, Moretti M, Zanardi A, Gaimarri A, Champtiaux N, Changeux JP, Whiteaker P, Marks MJ, Clementi F, Zoli M (2005) Heterogeneity and selective targeting of neuronal nicotinic acetylcholine receptor (nAChR) subtypes expressed on retinal afferents of the superior colliculus and lateral geniculate nucleus: identification of a new native nAChR subtype $\alpha 3 \beta 2(\alpha 5$ or $\beta 3)$ enriched in retinocollicular afferents. Mol Pharmacol 68:1162-1171.

Gotti C, Guiducci S, Tedesco V, Corbioli S, Zanetti L, Moretti M, Zanardi A, Rimondini R, Mugnaini M, Clementi F, Chiamulera C, Zoli M (2010) Nicotinic acetylcholine receptors in the mesolimbic pathway: primary role of ventral tegmental area $\alpha 6 \beta 2^{*}$ receptors in mediating systemic nicotine effects on dopamine release, locomotion, and reinforcement. J Neurosci 30:5311-5325. 
Horvitz JC (2000) Mesolimbocortical and nigrostriatal dopamine responses to salient non-reward events. Neuroscience 96:651-656.

Horvitz JC, Stewart T, Jacobs BL (1997) Burst activity of ventral tegmental dopamine neurons is elicited by sensory stimuli in the awake cat. Brain Res 759:251-258.

Kaneda K, Isa K, Yanagawa Y, Isa T (2008a) Nigral inhibition of GABAergic neurons in mouse superior colliculus. J Neurosci 28:11071-11078.

Kaneda K, Phongphanphanee P, Katoh T, Isa K, Yanagawa Y, Obata K, Isa T (2008b) Regulation of burst activity through presynaptic and postsynaptic GABA(B) receptors in mouse superior colliculus. J Neurosci 28:816-827.

Katsuta H, Isa T (2003) Release from GABA(A) receptor-mediated inhibition unmasks interlaminar connection within superior colliculus in anesthetized adult rats. Neurosci Res 46:73-83.

Kay JN, De la Huerta I, Kim IJ, Zhang Y, Yamagata M, Chu MW, Meister M, Sanes JR (2011) Retinal ganglion cells with distinct directional preferences differ in molecular identity, structure, and central projections. J Neurosci 31:7753-7762.

Kim IJ, Zhang Y, Meister M, Sanes JR (2010) Laminar restriction of retinal ganglion cell dendrites and axons: subtype-specific developmental patterns revealed with transgenic markers. J Neurosci 30:1452-1462.

Langer TP, Lund RD (1974) The upper layers of the superior colliculus of the rat: a Golgi study. J Comp Neurol 158:418-435.

Lee C, Kim J, Shin SG, Hwang S (2006) Absolute and relative QPCR quantification of plasmid copy number in Escherichia coli. J Biotechnol 123:273-280.

Léna C, de Kerchove D’Exaerde A, Cordero-Erausquin M, Le Novère N, del Mar Arroyo-Jimenez M, Changeux JP (1999) Diversity and distribution of nicotinic acetylcholine receptors in the locus ceruleus neurons. Proc Natl Acad Sci U S A 96:12126-12131.

Le Novère N, Zoli M, Changeux JP (1996) Neuronal nicotinic receptor $\alpha 6$ subunit mRNA is selectively concentrated in catecholaminergic nuclei of the rat brain. Eur J Neurosci 8:2428-2439.

Livak KJ, Schmittgen TD (2001) Analysis of relative gene expression data using real-time quantitative PCR and the $2^{-\Delta \Delta C(\mathrm{~T})}$ Method. Methods 25:402-408.

May PJ, McHaffie JG, Stanford TR, Jiang H, Costello MG, Coizet V, Hayes LM, Haber SN, Redgrave P (2009) Tectonigral projections in the primate: a pathway for pre-attentive sensory input to midbrain dopaminergic neurons. Eur J Neurosci 29:575-587.

McClure-Begley TD, King NM, Collins AC, Stitzel JA, Wehner JM, Butt CM (2009) Acetylcholine-stimulated $\left[{ }^{3} \mathrm{H}\right] \mathrm{GABA}$ release from mouse brain synaptosomes is modulated by $\alpha 4 \beta 2$ and $\alpha 4 \alpha 5 \beta 2$ nicotinic receptor subtypes. Mol Pharmacol 75:918-926.

Moretti M, Vailati S, Zoli M, Lippi G, Riganti L, Longhi R, Viegi A, Clementi F, Gotti C (2004) Nicotinic acetylcholine receptor subtypes expression during rat retina development and their regulation by visual experience. Mol Pharmacol 66:85-96.

Nashmi R, Xiao C, Deshpande P, McKinney S, Grady SR, Whiteaker P, Huang
Q, McClure-Begley T, Lindstrom JM, Labarca C, Collins AC, Marks MJ, Lester HA (2007) Chronic nicotine cell specifically upregulates functional $\alpha 4^{\star}$ nicotinic receptors: basis for both tolerance in midbrain and enhanced long-term potentiation in perforant path. J Neurosci 27: 8202-8218.

Paxinos G, Franklin KJB (2001) The mouse brain in stereotaxic coordinates, Ed 2. San Diego, CA: Academic.

Phongphanphanee P, Mizuno F, Lee PH, Yanagawa Y, Isa T, Hall WC (2011) A circuit model for saccadic suppression in the superior colliculus. J Neurosci 31:1949-1954.

Pons S, Fattore L, Cossu G, Tolu S, Porcu E, McIntosh JM, Changeux JP, Maskos U, Fratta W (2008) Crucial role of $\alpha 4$ and $\alpha 6$ nicotinic acetylcholine receptor subunits from ventral tegmental area in systemic nicotine self-administration. J Neurosci 28:12318-12327.

Salminen O, Murphy KL, McIntosh JM, Drago J, Marks MJ, Collins AC, Grady SR (2004) Subunit composition and pharmacology of two classes of striatal presynaptic nicotinic acetylcholine receptors mediating dopamine release in mice. Mol Pharmacol 65:1526-1535.

Salminen O, Drapeau JA, McIntosh JM, Collins AC, Marks MJ, Grady SR (2007) Pharmacology of $\alpha$-conotoxin mii-sensitive subtypes of nicotinic acetylcholine receptors isolated by breeding of null mutant mice. Mol Pharmacol 71:1563-1571.

Schmittgen TD, Livak KJ (2008) Analyzing real-time PCR data by the comparative $\mathrm{C}(\mathrm{T})$ method. Nat Protoc 3:1101-1108.

Schultz W, Romo R (1990) Dopamine neurons of the monkey midbrain: contingencies of responses to stimuli eliciting immediate behavioral reactions. J Neurophysiol 63:607-624.

Steinfels GF, Heym J, Strecker RE, Jacobs BL (1983) Response of dopaminergic neurons in cat to auditory stimuli presented across the sleepwaking cycle. Brain Res 277:150-154.

Strang CE, Renna JM, Amthor FR, Keyser KT (2007) Nicotinic acetylcholine receptor expression by directionally selective ganglion cells. Vis Neurosci 24:523-533.

Strecker RE, Jacobs BL (1985) Substantia nigra dopaminergic unit activity in behaving cats: effect of arousal on spontaneous discharge and sensory evoked activity. Brain Res 361:339-350.

Whiteaker P, Jimenez M, McIntosh JM, Collins AC, Marks MJ (2000a) Identification of a novel nicotinic binding site in mouse brain using $\left[{ }^{125} \mathrm{I}\right]$-epibatidine. Br J Pharmacol 131:729-739.

Whiteaker P, McIntosh JM, Luo S, Collins AC, Marks MJ (2000b) $\left[{ }^{125} \mathrm{I}\right]-\alpha-$ Conotoxin MII identifies a novel nicotinic acetylcholine receptor population in mouse brain. Mol Pharmacol 57:913-925.

Whiteaker P, Peterson CG, Xu W, McIntosh JM, Paylor R, Beaudet AL, Collins AC, Marks MJ (2002) Involvement of the $\alpha 3$ subunit in central nicotinic binding populations. J Neurosci 22:2522-2529.

Xiao C, Srinivasan R, Drenan RM, Mackey ED, McIntosh JM, Lester HA (2011) Characterizing functional $\alpha 6 \beta 2$ nicotinic acetylcholine receptors in vitro: Mutant $\beta 2$ subunits improve membrane expression, and fluorescent proteins reveal responsive cells. Biochem Pharmacol 82:852-861. 